University at Albany, State University of New York

Scholars Archive

Educational Theory and Practice Faculty

Scholarship

Educational Theory and Practice

$4-20-2011$

\title{
Sustaining Knowledge Building as a Principle-Based Innovation at an Elementary School
}

\author{
Jianwei Zhang \\ University at Albany, State University of New York, jzhang1@albany.edu \\ Huang-Yao Hong \\ National Chengchi University, Taiwan, hyhong@nccu.edu.tw \\ Marlene Scardamalia \\ University of Toronto, Canada \\ Elizabeth A. Morley \\ University of Toronto, Canada \\ Chew Teo \\ University of Toronto, Canada
}

Follow this and additional works at: https://scholarsarchive.library.albany.edu/etap_fac_scholar

Part of the Education Commons

\section{Recommended Citation}

Zhang, Jianwei; Hong, Huang-Yao; Scardamalia, Marlene; Morley, Elizabeth A.; and Teo, Chew, "Sustaining Knowledge Building as a Principle-Based Innovation at an Elementary School" (2011). Educational Theory and Practice Faculty Scholarship. 8.

https://scholarsarchive.library.albany.edu/etap_fac_scholar/8

This Article is brought to you for free and open access by the Educational Theory and Practice at Scholars Archive. It has been accepted for inclusion in Educational Theory and Practice Faculty Scholarship by an authorized administrator of Scholars Archive. For more information, please contact scholarsarchive@albany.edu. 
To appear in the Journal of the Learning Sciences

Running Head: PRINCIPLE-BASED INNOVATION

Sustaining Knowledge Building as a Principle-Based Innovation at an Elementary School

\author{
Jianwei Zhang \\ University at Albany, USA \\ Huang-Yao Hong \\ National Chengchi University, Taiwan \\ Marlene Scardamalia \\ University of Toronto, Canada \\ Chew Lee Teo \\ University of Toronto, Canada \\ Elizabeth A. Morley \\ Institute of Child Study, University of Toronto, Canada
}

Correspondence author:

Jianwei Zhang

University at Albany

1400 Washington Ave, ED 115B, Albany, NY 12222

Phone: (518) 442-4007; Fax: (518) 442-5008

Email: jzhang1@albany.edu 


\begin{abstract}
This study explores Knowledge Building as a principle-based innovation at an elementary school and makes a case for a principle- versus procedure-based approach to educational innovation, supported by new knowledge media. Thirty-nine Knowledge Building initiatives, each focused on a curriculum theme and facilitated by nine teachers over eight years, were analyzed using measures of student discourse in a Knowledge Building environment--Knowledge Forum. Results were analyzed from the perspective of student, teacher, and principal engagement to identify conditions for Knowledge Building as a school-wide innovation. Analyses of student discourse showed interactive and complementary contributions to a community knowledge space, conceptual content of growing scope and depth, and collective responsibility for knowledge advancement. Analyses of teacher and principal engagement showed supportive conditions such as shared vision; trust in student competencies to the point of enabling transfer of agency for knowledge advancement to students; ever-deepening understanding of Knowledge Building principles; knowledge emergent through collective responsibility; a coherent systems perspective; teacher professional Knowledge Building communities; and leadership supportive of innovation at all levels. More substantial advances for students were related to years of teachers' experience in this progressive knowledge-advancing enterprise.
\end{abstract}




\section{Sustaining Knowledge Building as a Principle-Based Innovation at an Elementary School}

\section{Introduction}

Creative knowledge work requires engagement with complex systems in changing and unpredictable social situations (Engeström, 2008; Gloor, 2006; Sawyer, 2007; Scardamalia \& Bereiter, 2006). Classroom innovations to facilitate creative knowledge practices require working with emergent rather than fixed goals and noticing and taking advantage of new opportunities rather than relying on fixed routines (Sawyer, 2004; Zhang, Scardamalia, Reeve, \& Messina, 2009). Accordingly, implementing such innovations requires creative engagement of teachers to continually improve classroom designs and practices based on principle- rather than procedure-based approaches to teaching (Zhang, 2010).

Can principle-based approaches that rely on emergent goals and teacher innovativeness be cultivated and lead to more effective engagement of students in school? To investigate this possibility and obtain a clearer account of principle-based innovation, the present study explores Knowledge Building pedagogy and technology (Scardamalia \& Bereiter, 2006) as a principle-based, school wide innovation in an elementary school.

$\underline{\text { Working with Principles for Classroom Innovations }}$

Degree of prescription, specification, and structure varies with different designs and implementations of learning programs (Collins, 1996), ranging from approaches that make use of highly scripted procedures to those that depend on opportunism and principle-based practices (Brown \& Campione, 1996; Hong \& Sullivan, 2009; Sawyer, 2004; Schwartz, Lin, Brophy, \& 
Bransford, 1999; Scardamalia \& Bereiter, 2007; Zhang, 2010). A scripted, proceduralized approach specifies tasks and activities, the order and form they should take, and tools and resources to be used. In some cases, teachers are required to follow word-for-word scripts (see Sawyer, 2004). Program designers thus exert centralized "remote control" over the teachers' practices (Brown \& Edelson, 2001; Tyack \& Cuban, 1995). A principle-based approach, in contrast, defines core values and principles, leaving to teachers the challenge of reflective interpretation, discretionary judgment, and adaptive classroom decisions to accommodate their different contexts and possibilities. Teachers are expected to not only invent but continually improve procedures derived from principles, with this process supported through use of knowledge networks to advance pedagogical understanding and decision-making. This principle-based approach echoes the development of principle-based practices in many social sectors in the Knowledge Age (Hitysse \& Kennedy, 1999). We might think of these contrasting practices and models for classroom innovation as falling along a continuum from procedure- to principle-based approaches. At the procedure-based end innovations are translated into school practice through specification of procedures to be faithfully implemented; at the principle-based end innovations are continually advanced through invention driven by analysis of principles, examples, and results.

Learning scientists, as a community, tend to emphasize teacher understanding of learning principles to support teacher adaptation and design (Barab \& Luehmann, 2003; Brown \& Edelson, 2001; Engle \& Conant, 2002; Linn, 2006; Penuel \& Gallagher, 2009). Without adherence to principles new learning models can easily be reduced to surface features and 
“cosmetic" changes (Brown \& Campione, 1996; Russell, 1998). For example, a teacher may interpret a change from individual to small-group work as an organizational change but not see the corresponding need to shift to more collaborative and distributed knowledge processes. As Brown and Campione (1996) indicated, principles "need to be understood if the procedures are to serve their original function." (p. 322) Researchers have defined and elaborated principles underlying several learning programs in light of current understanding of how students learn (e.g., Engle \& Conant, 2002; Linn et al., 2003; Brown \& Campione, 1996). Building on these various programs, a network of researchers has created a Design Principles Database (Kali, 2006). This database presents interrelated principles and corresponding design features and examples as a multi-level system, ranging from meta-principles that capture essential ideas to and guide classroom actions (e.g., making thinking visible) to pragmatic principles (e.g., provide a visual overview of the inquiry processes) and specific design features. Through use of the database researchers are engaged in collaborative sharing and advancement of design knowledge, but in its current form teachers are not involved as contributors to the evolution of the principles and design features.

The present study explores a principle-based approach to translation of principles into action, and toward this end identifies three points along a procedure- to principle-based continuum: (a) procedure based. (b) principle-based procedures, and (c) principle based. At the extreme procedure-based end, principles are not made explicit but must be inferred from procedures. These procedures typically involve carefully sequenced activities and curriculum material and pre-established prompts and scripts to keep learning progressions on course. At the 
midpoint--the principle-based procedure approach-- principles are made explicit and best practices are conveyed through pre-established activities and procedures that translate these principles into effective action. At the extreme principle-based end of the continuum principles are made explicit and presented as pedagogical design parameters with teachers and students engaged as innovators and developers in a research-intensive process involving continual improvement of principle-based practice. These three approaches are not meant to describe specific learning programs but rather to suggest the range of approaches used by learning scientists. Any single program might incorporate aspects of all three approaches, but typically educational approaches fall into the first two, reflecting the assumption that educational innovation requires "starter" lessons even "rituals," so plans, tasks, and activity sequences can be integrated into classroom procedures and become effortless in execution. After teachers have experience they can deal with the more abstract principles that underlie these procedures and adapt them to their local circumstances (see, for example, scripted collaboration reviewed by Dillenbourg, 2002 and Learning by Design--LBD--Kolodner et al., 2003; Kolodner, 2006). As Kolodner and colleagues explain,

"The rituals give each phase of the LBD cycle some flesh, providing specifics about how to carry them out and clear guidelines for weaving back and forth from phase to phase. Iteration has become a part of the classroom culture that everybody—students and teacher-understand the purpose of and make time for. " (Kolodner et al., 2003, p.536). In several other programs (e.g., Linn, 2006), procedures are conveyed through prompts for explanation, collaboration, reflection, and so forth. Brown and Campione (1994) used activity 
structures such as jigsaw, crosstalk, and benchmark lessons to establish Fostering Communities of Learners classrooms. They noted an important advantage of their approach: "The repetitive, indeed, ritualistic nature of these activities is an essential aspect of the classroom, for it enables children to make the transition from one participation structure...to another quickly and effortlessly." (p. 236) They also wrote about "lethal mutations" (Brown \& Campione, 1996) created by the fact that implementers often focus on surface features rather than the underlying principles, thus the procedures themselves became rituals that impede innovativeness. As they elaborate, the procedures lose their effectiveness because they are used too ritualistically and thus are not adapted to local contexts. Ironically then, rituals designed to enable innovation might come to stand in its way.

As a point of clarification, the Knowledge Building challenge is not to avoid tasks and activities or repeated enactment of effective procedures. Tasks activities, deadlines, and responsibilities, are essential components of any work situation. The challenge is to ensure that idea improvement rather than the completion of a specific task or routine is at the centre of the educational enterprise. If idea improvement is not happening, or is only happening for a limited number of community members, that is a sign that the tasks, activities, and routines need to be improved. Activity structures and procedures must constantly evolve in the service of idea advancement (Scardamalia \& Bereiter, 2006, 2007). And for that to happen, teachers and students need to initiate, monitor, and re-structure classroom activities as they proceed.

In the following section we elaborate ways in which teachers and students proceed without set procedures, using Knowledge Building pedagogy and technology to help them chart the way. 
Knowledge Building may well stand alone, far out on the principle-based end of the continuum, as a pedagogical model in use for several decades in nations spanning the Americas, Asia, and Europe, without prescribed procedures to keep it going. Pedagogical advances have depended on emergence of classroom procedures based on efforts to implement principles, with procedures evolving as teachers anticipate and experience roadblocks and find ways around difficulties. Teacher-researcher teams have formed in each nation committed to a research-intensive enterprise. Thus research results help guide the work at each site. Increasingly, analytic tools are being built into the software so that feedback is available on demand, directly to teachers and students (as teachers choose) to inform the work as it proceeds. Additionally virtual meetings and a Knowledge Building Summer Institute (http://ikit.org/summerinstitutes.html/) provide means for teachers to communicate and to spread the word about various innovations that have proved effective. There is general and open acceptance of the fact that principles represent an ideal state — something to strive for-and that the principles themselves are objects for discussion and continual improvement, as well as the procedures they inform. The model tends to attract teachers and administrators who see themselves as educational innovators.

\section{$\underline{\text { Knowledge Building }}$}

Knowledge Building pedagogy and technology attempt to refashion education in line with how knowledge work proceeds in a knowledge-creating culture (Scardamalia \& Bereiter, 2006; Scardamalia, Bransford, Kozma, \& Quallmelz, 2010). Knowledge workers build on and advance the knowledge assets of their community (Csikszentmihalyi, 1999; Sternberg, 2003) by generating and identifying promising ideas and improving them through incremental and 
sustained processes; by formulating deeper problems as solutions are developed; by engaging in idea-centered discourse involving multiple perspectives, constructive criticism, and distributed expertise; by committing themselves to creative goals and careers; by taking risks and by assuming leadership and responsibility at the highest levels instead of relying on the leader to tell them what to do (Amar, 2002; Bereiter \& Scardamalia, 1993; Dunbar, 1997; Florida, 2002; Sawyer, 2007). Correspondingly, knowledge-creating organizations provide supportive, organic, and flexible structures that encourage participatory and distributed control, adaptability, and emergent collaboration (Engeström, 2008; Gloor, 2006; Williams \& Yang, 1999).

Bereiter and Scardamalia treat knowledge building and knowledge creation as synonymous. A benchmark for school-based Knowledge Building communities is that they operate as knowledge-creating organizations, engaging learners in the process of knowledge creation from an early age. This is in contrast to educational approaches that focus on activities that are expected to lead eventually to knowledge creation as opposed to engaging directly in it. As part of an effort to engage students in a knowledge society (Scardamalia \& Bereiter, 1996), a Knowledge Society Network has been established that is open to teachers, students, researchers, engineers, policy makers, and members of the broad international community engaged in knowledge building. The network has existed for over 15 years (see Hong, Scardamalia, Zhang, 2010) and helps spread innovations and coordinate work in different locations.

There is an extensive literature on knowledge building. Most writers use the term to convey active learning, not knowledge creation. For the work reported here we use the term in a more specific sense, as defined by Scardamalia \& Bereiter (2003): “...the production and continual 
improvement of ideas of value to a community, through means that increase the likelihood that what the community accomplishes will be greater than the sum of individual contributions and part of broader cultural efforts. Knowledge building, thus, goes on throughout a knowledge society and is not limited to education." (p. 1371)

Through a set of 12 Knowledge Building principles (Table 1) Scardamalia (2002) has attempted to capture sociocultural and cognitive dynamics of knowledge creation as elaborated in the literature, and also to build on earlier research on transformative discourse (Bereiter \& Scardamalia, 1987), intentional learning (Scardamalia \& Bereiter, 1991), and creative expertise (Bereiter \& Scardamalia, 1993). Additionally, an effort has been made to identify principles that teachers and students can grasp--real ideas and authentic problems, idea improvement, rise above (Scardamalia \& Bereiter, 2007). Knowledge Building technology is designed to provide supports for translating the principles into practice, with indicators of progress related to the principles so as to break down barriers to implementing mature knowledge processes in schools.

Insert Table 1 about here

Within Knowledge Building communities, students engage in sustained idea improvement and collectively advance the "state of the art" of their community knowledge. They identify and work on problems of understanding, contribute their ideas to a public space, engage in progressive discourse and experimentation, and use a wide variety of resources. A networked Knowledge Building environment—Knowledge Forum, formerly known as CSILE 
(Computer-Supported Intentional Learning Environment) - has been developed to support the high-level knowledge processes and make the principles transparent to teachers and students. Table 1 shows correspondences between the technology and principles. Within this networked environment students create views (workspaces) in line with their knowledge goals, contribute ideas and questions by writing notes in the views, build on and reference one another's notes to make collaborative advancement, and rise above a cluster of notes to synthesize and re-conceptualize their understanding.

The 12 principles and corresponding technology create affordances for knowledge creation in a community, with the various components so intertwined and integral to day-to-day operations that efforts to isolate or prescribe procedures would undercut the dynamic that allows procedures to be continually improved. For this reason a principle- rather than procedure-based approach to classroom practices has been adopted, with teachers and their students co-constructing procedures that evolve to remedy limitations and accommodate new possibilities, and supports in place for sharing examples, bringing research to bear on their effectiveness, and in other ways facilitating continual improvement.

An essential component of Knowledge Building is making ideas explicit and public so they serve as conceptual artifacts (Bereiter, 2002) for the community and can be improved by any member. Knowledge Forum provides a shared electronic knowledge space for the community where members contribute and continually advance conceptual artifacts while developing personal expertise and identities. Bringing such community knowledge space to the classroom serves to inform and enhance a focus on collective knowledge advancement, with feedback, 
interaction tools, and scaffolds supporting individual contributions and learning as well as collaborative work. For example, there are customizable scaffold supports for theory development: "My theory," "I need to understand," "This theory cannot explain," "Putting our knowledge together," etc. (Scardamalia, 2004). These scaffolds are not designed as scripts, but rather as supports for highlighting and turning over to students high-level knowledge processes. In line with the intention to support emergent rather than scripted processes, use of scaffolds is not mandatory, there is no specified order or timing for their use, they are customizable and designed to support new discourse forms, and they serve as search parameters so that users can find all entries associated with scaffolds. For example, students can search for all theories about photosynthesis (e.g. all theories with the word photosynthesis and tagged with the scaffolds "My theory" or "This theory cannot explain").

To further help teachers and their students use Knowledge Building principles for design and reflection, the analytic tools mentioned above serve as indicators of principles in use, as well as providing feedback regarding advances for a broad range of $21^{\text {st }}$ century competencies (Scardamalia, 2003). These analytic tools operate in the background of Knowledge Forum to provide real-time, on-demand information about students' collective and individual performances. Consider, for example a, "standard best practice" in education that engages participants in collaborative production of a finished product to demonstrate individual or small-group learning. In contrast, the Knowledge Building principle collective responsibility for community knowledge shifts the focus to aspects of idea improvement that are frequently left out of project work--for example, taking responsibility for the overall advancement of the knowledge 
of the community, not simply the production of a finished product for a small group. Toward this end, and in line with information presented above, Knowledge Forum's collaborative workspaces hold all epistemic artifacts contributed by community members and automated social network analysis tools embedded in the environment help teachers and students visualize social interactions surrounding these artifacts (e.g., note reading, building-on, referencing, etc.). Collective engagement as well as individual roles can be analyzed (see Zhang et al., 2009). Students and teachers can use these tools to plan and reflect on contributions in light of various indicators of progress such as awareness of peer contributions (reflected in notes read across all views); interactive and complementary contributions (reflected in building on and referencing peers' notes); production of informative notes and views helpful for the community as a whole (reflected in revisions); and demonstrating conceptual interrelationships (reflected in linking notes and views) (also see Scardamalia, 2003; Zhang et al., 2009).

Overall, work within a complex, constantly evolving dynamic system is enabled through interrelated systems of support: Knowledge Building principles and Knowledge Forum technology broadly applicable to all classroom initiatives, analytic tools providing indicators of principles in use, and automated tools providing feedback to work as it proceeds. Thus principles and technology combine to provide mutually supportive contexts for high-level knowledge processes.

The system of interactivity and feedback to knowledge processes that results is very different from that established through activity cycles, step-by-step routines, and various other set procedures built into many educational enterprises. Teachers and students co-construct and 
reconstruct the flow of things as work proceeds, kicking-off a new inquiry through a new item entered into the database, rallying around an idea and formulating new problems to be addressed, deepening an inquiry by initiating new experiments, rising above previous accounts, and so forth. Visualization and feedback tools help the community identify and focus on the new effort. Overall, the process of knowledge creation is made transparent to teachers and students alike to help them sustain a principle-based approach, with less dependence on pre-established activity sequences to keep the knowledge work moving forward.

\section{Engaging Teachers' Innovative Capacity}

Sustaining principle-based innovation relies on teachers' innovative capacity and adaptive expertise. Adaptive expertise has been contrasted with routine expertise (Hatano \& Inagaki, 1986) which operates through reduction of complex problems to simplified, stabilized routines that are highly efficient and dependent on proceduralized practices; teachers who depend on routine expertise tend to find the need for adaptive expertise aversive (Crawford, Schlager, Toyama, Riel, \& Vahey, 2005; Darling-Hammond \& Bransford, 2005). In contrast, teachers engaged in adaptive expertise critically reflect on the adequacy of their knowledge, identify and deal with increasingly complex challenges, and engage in progressive problem solving as a matter of course (Bereiter \& Scardamalia, 1993; Crawford, 2007). As Feiman-Nemser (2001) characterize adaptive expertise, it's a matter of "turning confusions into questions, trying something out and studying the effects, framing new questions to extend one's understanding." (p. 1031) Sawyer (2004) conceptualizes creative teaching as disciplined improvisation: Facilitating co-construction of knowledge needs to embrace high-level improvisation, with the flow of the class emerging 
from actions and interactions of students and their teacher. Thus, a teacher needs to balance planned and emergent aspects of their work to meet the changing needs of the community and seize opportunities for creating new practice (Fishman \& Davis, 2006). As the teacher learning literature suggests, such creative dispositions and capabilities can be supported through creating an innovative professional community that encourages: (a) teachers' continual learning, deliberate investigation and experimentation, risk-taking, and reflection on enactment (Hargreaves, 1999; Krajcik, Blumenfeld, Marx, \& Soloway, 1994; Rogers, 2002; Wilson \& Berne, 1999); (b) collaboration and sharing in practice, collegial dialogues about student learning, and friendly critics (Ballantyne, McLean, \& Macpherson, 2003; Darling-Hammond, \& McLaughlin, 1995; Fogleman, Fishman, \& Krajcik, 2006; Laferriere, Breuleux, \& Allaire, 2007); and (c) teacher professional autonomy (Vescio, Rossa, \& Adamsa, 2008). The above conditions help to inform our analysis of teachers' creative engagement in implementing Knowledge Building. Examining a specific principled innovation, such as Knowledge Building, through multifaceted, multilevel datasets as reported below, helps to elaborate, contextualize, and expand conditions for creative engagement (c.f. Little, 2002).

\section{Focal Inquiry: The Institute of Child Study as a Knowledge Building School}

To examine the possibility and means of enacting Knowledge Building as a principle-based innovation, practices at an elementary school-the Dr. Eric Jackman Institute of Child Study (Jackman ICS), Laboratory School. Ontario Institute for Studies in Education, University of Toronto) - were examined. This school has been cited as a successful site of Knowledge Building (Bielaczyc \& Collins, 2006) and represents an important case of sustained, 
school-wide, principled innovation. . The school was established in 1926, partly inspired by the work of John Dewey. It enrolls approximately 200 students from Nursery (Pre-K), Junior Kindergarten, Senior Kindergarten, to Grade 6, with 22 students on average per class. There is a classroom at each grade level, with the fifth- and sixth-graders working in two Grades 5/6 combined classrooms. Most families come from a middle class background and pay a tuition fee. Students are enrolled based on the order of application without pre-selection, with $44.5 \%$ being visible minorities and $10 \%$ receiving tuition support. At the point of this study, 15 full time teachers were employed, including a librarian, two French teachers, a special education teacher, an art teacher and a physical education teacher, with the principal having been on her post for over a decade. As a laboratory school, Jackman ICS has been involved in initiating and disseminating new ideas related to improving education. It makes daily contributions to teacher training, providing internship opportunities for graduate students in the programs of child development and education. Knowledge Building pedagogy and CSILE/Knowledge Forum were first introduced in 1994, tested by a few classrooms between 1996-2000, and adopted across the entire school since 2000. A teacher-researcher was hired by the CSILE/Knowledge Building project for the first several years to support start-up and to help document those early years.

The present research explores three related issues: (a) Can teachers and students in a school effectively enact and advance Knowledge Building as a principle-based innovation? (b) What efforts are necessary to sustain this principle-based innovation? (c) What conditions created by the school community support teachers' efforts? These questions are addressed through a mixed-methods design that integrated quantitative and qualitative data analyses (Creswell, 2008). 
The first question - mainly addressed through Part 1 of this research — is investigated through examining student online discourse in Knowledge Forum in 39 Knowledge Building initiatives facilitated by nine teachers over eight years. Data were analyzed using several quantitative measures of student engagement in collaborative knowledge building. The second and the third question are mainly addressed in Part 2, through qualitative analysis of teacher interviews, teacher journals, classroom observations, and observations of weekly Knowledge Building meetings attended by teachers, the principal, and researchers. The quantitative analyses in Part 1 and qualitative analyses in Part 2 complement and cross-validate each other in addressing the three questions that frame our inquiry into Knowledge Building as a principle-based innovation.

\section{Part 1: Analyzing Knowledge Building Initiatives Facilitated by Teachers}

\section{Knowledge Building Initiatives}

From 1996 to the present the teachers at Jackman ICS have facilitated a large number of Knowledge Building initiatives, Pre-K through Grade 6, with the support of Knowledge Forum. Each initiative investigated a core area of the curriculum, for example, weather, environment, plants, worms, light, sound, human body, earth, space, electricity, communities, North American history, Medieval culture, ancient civilizations, traditions, and so forth. In Pre-K, Kindergarten, and Grade 1 classrooms, students often create discussion notes with teacher help. Given the limited amount of text production at these early ages, Knowledge Forum does not contain extensive log data for each of these young students. Therefore, analyses were focused on Grades 2-6, taught by nine teachers during the period of 1999 - 2007. We selected the 39 Knowledge Building initiatives that spanned four weeks or more. Table 2 shows the number of initiatives 
facilitated by teachers with different years of Knowledge Building experience in different grades.

Insert Table 2 about here

\section{Data Sources and Analyses}

Each Knowledge Building initiative involved face-to-face discussions, experimentation, reading and online work. In all cases, students generated problems of understanding (e.g., how are rainbows made?) and identified deeper issues as their understanding deepened (e.g., why are the colors in rainbows always in the same order?). While offline they conducted experiments and observations as individuals and in small groups, searched libraries and the Internet, engaged in individual and cooperative reading, and designed experiments to address questions they raised. They initiated and participated in whole-class Knowledge Building conversations in which they shared their findings and built on each other's input to develop and examine diverse ideas, co-construct coherent understanding, identify deeper questions, and work towards increasingly sophisticated conceptualizations. Mirroring and enhancing these offline processes, they worked online to contribute their problems, theories, data, and resources to Knowledge Forum and to engage in Knowledge Building discourse. Figure 1 provides three screenshots of the Knowledge Forum discourse in three Knowledge Building initiatives, conducted in Grades 2, 3 and 5/6, respectively. Following principle-based practice, the teachers did not set task requirements for students such as number of notes to write, read, or build on in Knowledge Forum. Rather, students were encouraged to use the environment to support their inquiry; if they were not 
contributing, they were reminded that their contributions were important, for their own work and for that of the community. Similarly students were encouraged to build on each other's notes to help improve the collective work. Student contributions and interactions provided data for analysis in Part 1.

Insert Figure 1 about here

Analytic tools underlying Knowledge Forum (Burtis, 2002) were used to analyze student participation and interaction including note creation, problem statements in notes, note reading, and note linking through build-ons, rise-aboves, and reference citations. Student interaction in the online discourse was further analyzed using social network analysis (Scott, 1991). Social network analysis provides methods for examining social interactions in a community based on mathematical graph theory. In a social network, each actor is represented as a node; a relational tie between two actors is represented as a line. A variety of indicators can be used to examine the holistic patterns of a network (e.g., density, centrality) as well as the positions of individual members in it (e.g., indegree, outdegree, power). This study used social network analysis to look at two types of social interactions: who had read whose notes and who had linked to whose notes. The note reading and note linking interactions for each Knowledge Building initiative were represented as case-by-case (member-by-member) matrices, with values indicating the frequencies of interactions between each pair of participants. We used two basic measures to look at students' note reading and linking networks: (a) Inclusiveness, which refers to the 
percentage of non-isolated nodes in a social network; and (b) Density, which is gauged by the number of lines (node-to-node connections) divided by the maximum number of all possible lines (Scott, 1991), with a value varying between 0 and 1. In a high-performing Knowledge Building community, members should learn about and build onto peers' inquiries, resulting in high inclusiveness and densities in the note reading and linking networks.

The above analyses measured student knowledge building along three dimensions (Zhang et al., 2009): (a) Student contributions to a community knowledge space, based on the number of notes created and number of problems worked on by each student; (b) Awareness of contributions made by other members, measured using inclusiveness and density of the note-reading network (who read whose notes); and (c) Interactive and complementary effort to build on and rise above (e.g., synthesize, connect, reorganize, re-conceptualize) peers' work, as measured by the inclusiveness and density of the note-linking network (who built on, rose above, or referenced whose notes).

Due to the large number of inquiry initiatives analyzed, this study did not include in-depth content analysis of students' discourse. However, earlier studies have employed a combination of analyses, including social interaction (e.g., note contribution, reading, linking), content analysis (e.g., questioning, idea improvement, resources use), and linguistic analysis (e.g., academic words, domain-specific words). Significant correlations have consistently been found between the quantitative measures of social interaction and content-based measures of knowledge advances (Sun, Zhang, \& Scardamalia, 2010; Zhang et al., 2007; Zhang et al., 2009, Zhang \& Sun, 2008). 


\section{An Overview of the 39 Knowledge Building Initiatives}

To understand the duration of a Knowledge Building initiative, we looked at its time span from the first to the last note that was entered into a Knowledge Forum view specifically related to the theme under investigation. It is important to note, as suggested above, that Knowledge Building typically involves a significant amount of offline discussion, experimentation and other activities preceding the first and following the last note created online. Based on the online component alone, each Knowledge Building initiative lasted 159.24 days on average $(\underline{\mathrm{SD}}=$ 97.11, $\underline{\text { Median }}=156.00)$. As a stricter measure of time investment, we further counted the number of "Knowledge Forum active days," each of which had at least one new note contribution. Students in this study typically used Knowledge Forum as a part of their classroom study at school, not from home, and new notes are typically generated in the course of classroom inquiry. Each initiative had an average number of $29.87(\underline{\mathrm{SD}}=19.17$, Median $=31)$ "Knowledge Forum active days." The initiatives emerged from students' interests and addressed core disciplinary themes, so one Knowledge Building initiative was frequently related to another (e.g., between light and sound; water and weather; tradition, civilization, and community).

\section{$\underline{\text { Student Contributions to the Community's Knowledge Space }}$}

As a measure of student contribution to a community knowledge space, we analyzed the number of notes created by each student in each initiative (Figure 2). This number is between 5 and 20 for most of the initiatives. A multilevel mixed model analysis was conducted to examine the effects of student grade level (lower versus upper grade) and the teachers' Knowledge Building experience (first, second, third year or later) on student contribution, using "Knowledge 
Forum active days" as a covariate. Significant effects were found for teachers' Knowledge Building experience $(\underline{F}(2,759)=26.48, \mathrm{p}<.001)$, student grade $(\mathrm{F}(1,759)=5.41, \mathrm{p}<.05)$, as well as the number of "Knowledge Forum active days" $(\underline{F}(1,759)=515.92, \underline{p}<.001)$. With more experience, teachers could engage students more actively in sustained Knowledge Building discourse. Interestingly, students in Grade 2 and 3 created more notes than those in upper grades, although a word count indicated that their notes were overall much shorter than those by older students.

Insert Figure 2 about here

Knowledge Forum has a "problem" field to indicate the focal problem of each note. A group of third-graders identified the following focal problems in their notes in an inquiry of worms: How do worms move? Why do worms have segments? How can worms move through hard soil? How do worms make soil? How can worms survive? Can worms sense light? Analyzing students' problem statements provides information about the conceptual scope of their discourse as well as sustained effort to identify and address deeper challenges as they build knowledge in a content area (Hakkarainen, 2003; Zhang et al., 2007). This problem statement feature is optional, and as a result, three of the Knowledge Building initiatives did not explicitly use this feature and were thus excluded from the analysis of student problem statements. Focusing on the number of problems worked on per student in the remaining 36 initiatives, we ran a multilevel mixed model analysis, using student grade level and the teachers' Knowledge 
Building experience as between-group factors and "Knowledge Forum active days" as a covariate. A significant interaction effect was found between teachers' experience with Knowledge Building and student grade level $(\underline{\mathrm{F}}(2,715)=20.01, \underline{\mathrm{p}}<.001)$, along with a significant main effect for teacher experience $(\underline{\mathrm{F}}(2,715)=14.33, \underline{\mathrm{p}}<.001)$ and "Knowledge Forum active days" $(\underline{F}(1,715)=245.54, \underline{p}<.001)$. In initiatives facilitated by more experienced Knowledge Building teachers, each student identified and worked on more problems related to the theme of inquiry; this trend was more compelling among students of Grades 4-5/6.

Insert Figure 3 about here

\section{Awareness of Contributions}

In Knowledge Forum, students develop awareness of peers' contributions (e.g., problems, new understandings) and benefit from advances by reading each other's notes. An earlier study indicated a significant correlation between note reading and knowledge gained (Zhang et al., 2007). Being able to determine where progress is being made within the community and knowing who is working on what helps community members understand the evolution of their inquiry and shared goals, and thus they are better able to consult others' work and find appropriate partners (Engle \& Conant, 2002; Palincsar, Anderson, \& David, 1993; Zhang et al., 2009). There is no need for fixed group structures; rather, students can form and reform into working groups as participants find mutually beneficial. We applied social network analysis to the log data of who had read whose notes and computed the inclusiveness and density of note 
reading contacts in each Knowledge Building initiative. The inclusiveness of the note reading network was close to $100 \%$ in each initiative, indicating that every student was a part of the communal information flow enabled through note reading. The density of note reading was also very high $(\underline{\mathrm{M}}=.80, \underline{\mathrm{SD}}=.23, \underline{\text { Median }}=.84)$. There was a trend of growth in the density of note reading associated with teachers' Knowledge Building experience (Figure 4), although not statistically significant $(\underline{p}>.10)$ possibly due to a ceiling effect.

Insert Figure 4 about here

\section{$\underline{\text { Interactive, Complementary, and Connected Contributions }}$}

Collaborative knowledge construction requires that students respond to and build on one another's ideas (Palincsar et al., 1993) and contribute non-redundant and important information so the group can make progress. Knowledge Forum supports student collaboration through a set of interaction and "rise above" tools, as suggested above. Earlier content-based analyses (Zhang et al., 2007) of a Grade 4 class revealed that students engaged in a wide range of productive interactions, as indicated by the following discourse moves: develop and elaborate peers' ideas (e.g., That's true, I think that..., Here are some examples of...); contribute alternative ideas (e.g., I disagree, because...); identify questions and challenges (e.g., I need to understand..., What about...? What's your evidence?); provide related information from readings and suggest further inquiry (e.g., Can you think of a way to test your theory?); and synthesize the group's understanding and achieve new insights (e.g., Here's a summary). To examine students' 
collaborative effort, we analyzed the social network of student note linking contacts: who had linked to whose note through building on, referencing, or rising above. The overall inclusiveness of the networks was quite high, with an average of $75.54 \%(\underline{\mathrm{SD}}=27.97)$ sending out and $77.58 \%$ $(\underline{\mathrm{SD}}=27.83)$ receiving note-linking contacts per student in each of the 39 Knowledge Building initiatives. The densities of the note-linking networks varied considerably $(\underline{\mathrm{M}}=.26, \underline{\mathrm{SD}}=.26$, $\underline{\text { Median }}=.17$ ). To examine the effects of the teachers' Knowledge Building experience and student grade level on the network density of note linking in each Knowledge Building initiative, we ran an analysis of variance (ANOVA) using "Knowledge Forum active days" as a covariate (Figure 5). The ANOVA demonstrated a marginally significant effect for teacher experience ( $\underline{F}$ $(2,32)=3.14, \underline{p}=.057$, partial $\left.\underline{\eta}^{2}=.16\right)$, along with a significant effect for "Knowledge Forum active days" $\left(\underline{\mathrm{F}}(1,32)=30.44, \underline{\mathrm{p}}<.001\right.$, partial $\left.\underline{\underline{p}}^{2}=.49\right)$. There was a consistent growth in the density of note linking contacts associated with teachers' Knowledge Building experience.

Insert Figure 5 about here

\section{Discussion}

Analyses of note reading and note linking interactions indicate that teachers, even in their first year with Knowledge Building, created engaged and connected Knowledge Building communities. As the teachers proceeded, they were able to facilitate Knowledge Building with more elaborated and sustained contributions, as indicated by process-based interaction measures such as the number of notes students created, problems worked on collaboratively, and increases 
in complementarity of these efforts (building on, referencing, and rising above). These measures suggest increasing quality of students' collaborative knowledge work facilitated by teachers. Analysis of student-identified problems indicates the growing conceptual scope and depth of the online discourse. Earlier studies have indicated that these measures are significantly correlated with depth of understanding (Zhang \& Sun, 2008). A recent study that focused on one teacher provided detailed accounts of his classroom processes and how they improved over a three-year period; there were corresponding increases in student learning outcomes demonstrated through content analysis of student day-to-day discourse, their portfolios, and pre- to post-test results (Zhang et al., 2007; 2009). Detailed accounts of several other teachers' classrooms are also available in the literature (e.g., Caswell \& Bielaczyc, 2002; Pelletier, Reeve, \& Halewood, 2006).

Results from another study (Sun et al., 2010) showed extended and productive writing for students in Grades 3-4, suggesting that Knowledge Building communities can be developed at the early elementary level. Additional research involving note content analysis, patterns of participation and collaboration, and teachers' strategies for facilitating student work will be needed to explain more active contribution rates for younger students.

\section{Part 2: Understanding Teacher Efforts and School Conditions}

\section{$\underline{\text { Data Sources and Analyses }}$}

Part 2 focuses on understanding the efforts of the teacher and school community to sustain and improve Knowledge Building. Data sources included interviews with the teachers and the principal, teacher journals, classroom observations, and observations of weekly Knowledge 
Building meetings.

A semi-structured interview was conducted with the principal and 10 teachers who had been using Knowledge Building pedagogy supported by Knowledge Forum software. There were eight classroom teachers teaching Junior and Senior Kindergarten and Grades 1-6; a librarian; and a physical education teacher (art, special education, and other specialty teachers were not included in this analysis). Four of the teachers had been conducting Knowledge Building for three or more years; four were in the second year, and two were in the first year using Knowledge Building / Knowledge Forum. Each teacher interview took approximately 30 minutes, with focus on teaching goals, the teacher's role in facilitating Knowledge Building, advances and challenges, and school community support (see Appendix 1 for questions). The interview with the principal took an hour and focused on goals of teaching, teacher roles, and the school contexts and support for Knowledge Building. The interviews were videotaped and transcribed for comprehensive coding.

Additionally, intensive observations were conducted in Grades 1-5/6 classrooms to understand the Knowledge Building designs and processes at different grade levels. Teachers' journal entries, recorded in Knowledge Forum as "Calendars of Inquiry (COI)" were also analyzed. The teachers recorded their Knowledge Building designs, classroom processes, and reflections on advances and challenges. Six of the participating teachers had written extensively in their reflection journals over multiple years, and the average number of words produced in each teacher's journal was 174,808 $(\underline{\mathrm{SD}}=29,134.67)$ (see Hong et al., 2009 for detailed analysis). We also observed weekly Knowledge Building meetings — approximately 1.5 hours each week, 
over 2.5 years-where the teachers and the principal talked about their current classroom work, advances, and challenges. Approximately 80 pages of meeting minutes were recorded.

Systematic data analyses focused on interview data, with field observations (i.e., classroom practice, teacher meetings) and the teachers' reflection journals used to triangulate and enrich findings from the interview data. Two coders read and re-read the interview transcriptions and coded the teachers' responses following inductive data analysis (Hatch, 2002; Strauss \& Corbin, 1998). The analysis involved four iterative phases: (a) identifying initial categories based on the teachers' responses to each interview question; (b) identifying similarities and differences among the initial categories and creating integrated categories across different interview questions; (c) aggregating the categories into fewer, more encompassing themes - major factors that enable and sustain Knowledge Building practices; and (d) refining and validating the themes through relating and comparing the themes, checking data against the themes, and triangulating the identified themes with data from the teachers' journals and field observations. An initial summary of the themes was sent to the principal and a teacher for comment and feedback, which helped us to validate and fine-tune our interpretations (c.f., Creswell, 2008). Through the above process, six salient themes were formulated, as summarized in Table 3 and elaborated below.

Insert Table 3 here

Shared Vision, High expectations, and Agency in Knowledge Work 
The teachers developed a shared vision for their pedagogical practices - a vision that included high expectations for student learning in line with the principles and ethos of Knowledge Building: fostering student agency and high-level responsibility for collective knowledge advancement (Scardamalia \& Bereiter, 2006).

To understand their vision and beliefs of learning and teaching, interviewers encouraged the teachers and the principal to elaborate the three most important qualities to be developed in their students and to explain how they develop those qualities. Goals frequently identified included developing social character--factors such as confidence, caring, respect, and collective responsibility; intellectual curiosity and enthusiasm; and self-directed inquiry reflecting a desire to continually deepen their knowledge. As for the role of the teacher, the focus was on creating an open and safe environment--a respecting, responsible, and reflective community to help each student learn, inquire, and grow. With respect to deepening knowledge, goals included encouraging risk-taking with ideas, so students feel safe advancing their early and ill-informed ideas, with the assurance that doing so enriches the resources of the community and supports the essential dynamic of continual improvement of ideas. Their explorations were aimed at doing justice to curriculum mandates, but they were clear that their curricular goals should not be circumscribed by these mandates; rather, their challenge was and remains that of exceeding expectations.

In line with Knowledge Building goals, especially the principle of epistemic agency, the teachers and the principal hold high expectations for what young students can accomplish. They trust that children can take on high-level responsibility in the classroom, including responsibility 
for generating meaningful questions and themes to deepen inquiry; for contributing and collaboratively improving their ideas; and for reflecting on and improving their thinking, participation, and collaboration. The teachers communicate their trust and expectation to students through daily classroom interactions, encouraging idea diversity and collective responsibility for continual idea improvement initiated and sustained through student action. As a result, student agency and respect for authoritative sources (e.g. experts, books) are facilitated. Knowledge Building supports students in the understanding that to build knowledge one needs to understand its historical roots as well as the "thought of the day" so they can build upon ideas that are not simply of their own invention (Zhang \& Messina, 2010). Of course, especially at early ages, the teacher helps direct and deepen their inquiry, encouraging them to ask questions and rather than judging ideas as right or wrong, considering ideas from different perspectives, and asking how they might be improved. As a Kindergarten teacher commented in the interview, "I want the students to make...purposeful choices about how they spend their time in the class. ...They don't need to have a teacher there guiding them in the whole way and telling them what they're doing is right or wrong." As another example, a Grade 5/6 teacher said in the interview:

"The other thing [to develop among students] is ... a feeling maybe of empowerment that they are able to contribute knowledge... And along with this empowerment comes this understanding that theories are improvable. The theories that are presented in a textbook or in a lesson are the theories that simply have the most, the best research to support them. But there are other existing theories or other theories that haven't yet been presented that might improve upon that idea, and that the students themselves might be the people who contribute 
that knowledge."

Teachers often reported being impressed by students' deep thinking and insights. The aforementioned Kindergarten teacher commented: "My soul gets constantly amazed by what these young children can accomplish." A Grade 4 teacher made a similar comment saying: "Sometimes in presenting a question and stepping away, the children can take hold of it and go in directions that...I couldn't even imagine." And as the children take on greater responsibility this helps the teacher envision new possibilities in student learning and development and identify additional opportunities for incorporating new, improved strategies. A positive feedback loop thus forms: the teachers foster student agency and are rewarded with exciting observations and positive student engagement, leading to deepening understanding of student agency, expanded visions of educational opportunities, and new experimentation.

In light of their understanding of student agency and potential, the teachers adjust their role so that students can take on high-level control. In the interviews, the teachers were asked to identify three most important advances they had made in teaching. Understanding young students' agency and adjusting their role accordingly emerged as a central theme, confirming findings from an earlier study of international Knowledge Building teachers (Lamon, Laferriere, \& Scardamalia, 2005). For example, a Pre-K teacher commented: "When I first tried out [Knowledge Forum] in my classroom, I experienced a seismic shift in my belief in how children in the early years can share ideas in order to come to a deeper understanding... Over the years, I have consciously worked on ways to release agency in a classroom of Pre-K children in a way 
that is meaningful to them."

Along with their belief in student agency in learning, the teachers demonstrate agency and ownership over their teaching practice, dedicated to advancing their pedagogical understanding, experimenting with new classroom designs, and going beyond best practice. As a Kindergarten teacher said: "I never try to think that worked really well, I'm going to do the same thing again. I always look for ways to improve my practice." The teachers continually develop new visions - visions of possibilities not yet fully discernible in education (Bereiter, 2002). They rethink their own practice, construct new expectations about student outcomes and new classroom roles, and teach in ways they have never taught before (Darling-Hammond \& McLaughlin, 1995). This disposition towards continual improvement and innovation is critical for teachers to develop adaptive expertise and practice as opposed to ritualized efficient routines (Crawford, 2007).

\section{Ever-Deepening Understanding Aided by Design, Reflection, and Research}

Teachers were all aware of Knowledge Building principles and indicators relevant to features of Knowledge Forum (e.g., features that support collaborative work, idea improvement, rise above). New teachers additionally reported observing and discussing classroom interactions with veterans, usually more experienced teachers in their school but also teachers at the yearly Knowledge Building Summer Institute (http://ikit.org/summerinstitutes.html), which has run continuously since 1997. At the Summer Institute ART (Analyses, Reflections, and Tours) sessions are organized to create partnerships between teachers and researchers. Teachers elaborate and reflect on classroom designs and teachers and researchers work together to analyze 
their work and envision new designs and uses of analytic tools in Knowledge Forum. Video recordings of these sessions are posted online as a resource for teachers.

As indicated above, standard classroom procedures have not been provided; rather, teachers share their designs and deepen their understanding of the principles as they test and reflect on their designs in specific contexts and content areas, supported by discussions of classroom examples. Teachers and the principal meet weekly to discuss their designs, practices, challenges, and opportunities, with the goal of exchanging insights and continually advancing practice.

Teachers engage in cycles of reflective inquiry regarding principles and classroom designs and practices, supporting progress in problem solving (see also, Hong et al., 2009). Pursuing possibilities surrounding Knowledge Building principles helps the teachers develop new ways of viewing classroom processes and identifying new possibilities as goals to direct their teaching. By creating and testing teaching designs in specific classroom contexts, challenging pedagogical, curricular, and technical issues arise, driving the teachers to modify and extend their designs. They co-participate in the knowledge building processes with their students and reflect on the processes (e.g., Are students building on each other's input for sustained improvement of ideas?). Such reflections are often aided by the use of Knowledge Forum and its analytic tools as these help teachers and students identify issues and practices consistent or seemingly at odds with the principles. The teachers also discuss advances in understanding, classroom designs, indicators of progress, and classroom data at teacher meetings. Table 4 lists some of the teachers' designs and strategies, as examples, in line with Knowledge Building principles. 
Insert Table 4 about here

To further elaborate the sustained cycles of principle-based understanding, design, and reflection, we specifically analyzed the teachers' efforts to enable and facilitate Knowledge Building discourse. Knowledge Building discourse, as a principle, refers to discursive practice that results in not only sharing of knowledge, but also refinement and transformation of knowledge and emergence of new ideas (Scardamalia, 2002). Knowledge Forum supports Knowledge Building discourse as a continuation and enrichment of classroom conversations, as there are technological affordances for revising, building-on, referencing, annotating, summarizing, and clustering notes based on conceptual goals, with customizable scaffolds supporting specific cognitive operations (e.g., theory building). The analysis tools then provide feedback about evolving conversation threads, progressive questions, key terms, and scaffold use. Understanding the principle of Knowledge Building discourse and related technological tools helps the teachers envision new structures of discourse in classrooms. For example, a classroom conversation structure has evolved called "Knowledge Building Talk" (KB Talk).

KB Talk had its roots in "crosstalk." In 1998, teachers were introduced to "crosstalk"—a design used in the Fostering Community of Learners framework to enable information sharing across groups, with students from different small-groups exchanging information about their progress and asking each other questions (Brown \& Campione, 1994). The teachers-including a teacher-researcher - modified crosstalk in light of the principles of Knowledge Building and developed KB Talk that focuses primarily on sustained idea improvement (Reeve, 2001). 
Students typically sit in a circle with the teacher as a member of the group contributing to the conversation and modeling careful listening, constructive criticism, and progressive analysis of problems and issues. A teacher-student invention that has spread is the idea that the talks should be cancelled if students have not indicated in advance issues requiring concentrated teacher-student time. Since students share and build on each other's ideas continuously in Knowledge Forum they do not need to use whole group time to share ideas, but rather reserve it for times when they are stuck or feel they could make more progress in refining goals, establishing next steps, or in other ways advance the discourse. Instead of having the teacher decide the what-who-how-when of discussions, students propose problems and ideas for KB Talks. While teachers have incorporated the "handing off" procedure used in "crosstalk" (the current speaker chooses the next speaker )they continue to experiment with this, as suggested below. The goal of KB Talks as conveyed to students is to progressively advance understanding and engage in meta-discourse to reflect on progress (e.g., is the discourse getting anywhere?), formulate emerging problems, and develop action plans to address problems (Scardamalia \& Bereiter, 2007). Below is an excerpt from a KB Talk episode in a Grade 4 classroom studying optics (Zhang \& Messina, 2010). The conversation preceding this episode focused on how opaque objects interact with light and led to the understanding that opaque objects, including those with rough surfaces such as bricks, reflect light. Questions were raised concerning how objects of different colors reflect light, with the green carpet in the classroom as an example.

S1: Even if light didn't bounce off of it [carpet], it would still be green... 
Teacher: S2, you said something [different] earlier...Did you hear what she [S1] said? ...

S2: Maybe you can only see things if there's light bouncing off of them. Maybe you see them as black if there is no light. [Looked at people raising hand and picked S3]

S3: When you turn off the lights, everything goes black maybe that is because the light isn't bouncing off of it so you can't see it. [Looked at people raising hand and picked S4]

S4: If you, if this room [were] totally black, the carpet would still be green...but you wouldn't see it because there's no light to bounce off of it so you couldn't see the color...

Teacher: $\mathrm{S} 1, \ldots$ does that make any sense to you?

[Several students talked at once] You can still see green...

S5: ... You don't need the light for it to be green. You need the light for it to be green to you...to your eyes.

S6: Well, you don't need the light to make the carpet green you just need the light to see that the carpet is green.

Teacher: Just, I don't understand. When we're talking about green light. I see a green carpet as we all say we do. But I see a white light, so how are we saying there's green light here.

[Discussion continues, addressing the concept of white light as a mix of primary colors.]

In this KB Talk, the students explored how light interacts with opaque objects and objects of different colors and how people see colors. They contributed and examined diverse ideas addressing issues related to white light, primary colors, light reflection, and color vision. The teacher indicated an issue he did not understand, modeling an important move. He engaged in 
careful listening, fostered conceptual connections and coherence, and raised issues corresponding to core disciplinary concepts (Zhang \& Messina, 2010).

Classroom observations and interview data show that the teachers do not proceduralize KB Talk, but improvise and continually evolve more effective strategies. A Grade 3 teacher commented in the interview: "I played around with it [KB Talk] a lot, ...trying to have children talk to each other without putting their hands up, so that if their ideas build on to someone else's, they can just say it." Similarly, a Grade 5/6 teacher reflected on his improvements to make KB Talk more flexible and spontaneous, saying:

"When I first started, KB Talk was on the schedule. They were every Tuesday 10 o'clock. I realized that wasn't working, because sometimes we...had nothing to talk about. Then...we have pockets [envelopes] on the board, and if you have something to talk about, you would write it on a piece of paper... That was better, but still a bit too prescriptive. What's happening now... is I don't necessarily plan a KB Talk. But they become more spontaneous. KB Talks always used to be sitting down in a circle; that is not the case any more. It could be in the classroom, someone sits in the chair, someone sits on the floor, as long as everyone is following... Much less structured, more organic, spontaneous. " (Interview on November 24, 2006)

Over the years the teachers have developed a number of strategies to support productive KB Talk, as the following examples suggest: (a) The "idea ball" metaphor: The teacher encourages students to think in terms of carrying an idea (ball) that they are trying to take to a goal, requiring that it be passed effectively from one member to another to facilitate collective contribution and 
advances toward a goal; (b) Integrating online and offline Knowledge Building discourse: A projector is used so students' contributions to Knowledge Forum are displayed on a screen during a KB Talk, to encourage them to think in terms of "community knowledge"-- noting specific ideas and isolated entries that should be referenced, assembling evidence, identifying emergent goals and connections, and determining next steps; (c) Metadiscourse: Students are encouraged to take a more comprehensive look at what they are doing by shifting between content-specific discussions and metadiscourse (e.g., "Are we getting anywhere? "Is there an important idea we're missing?"), thus supporting goal-setting, planning, and review of current procedures and processes; (d) Discipline-specific adaptations of KB Talk: Theory development is scaffolded within Knowledge Forum, as indicated above, and teachers adapt it to different content areas (e.g. history, mathematics, language arts) to support progressive discourse; and (e) Summarization: Students are asked to summarize big ideas developed during a KB Talk, using words or visuals. These are but a few of the techniques teachers have developed to support emergent needs in different content areas and for students at different levels.

As teachers develop and implement designs such as KB Talk they engage in real-time action and then reflection, often using Knowledge Building principles to assess the adequacy of a new design: Are idea improvements evident--are students focusing on "big ideas," promising questions, evidence? Are they generating probing questions and going deeper? Are they taking responsibility for community knowledge?

An issue that is frequently discussed is when and how often a teacher should intervene in a knowledge building process. Will doing so detract from students' epistemic agency? A Grade 3 
teacher wrote in her first year's reflection journal: “The whole notion of a Knowledge Building community is something that ... has to be made much more explicit. Our investigations have to have a clearer agreed upon direction. ... Many students honed in on individual questions and connected only minimally to their classmates." Identifying these problems helped the teacher to develop more effective designs. She recognized the need to incorporate whole class conversations as early as possible to help define the goal of the community and increase students' collective responsibility. Critical reflection of this kind can be vital when unfavorable situations occur. For example, a Grade 5/6 teacher noted student resistance to writing notes in Knowledge Form. His critical reflection on this problem led him to realize an important reason: Sometimes the students were asked to use Knowledge Forum in ways that discourage its use. For example, if everyone is using it to write down factual information about the same question and there is little idea-centered work or authentic problem solving, reading the database becomes quite boring. He reflected: "I really wait until it makes sense... What I found in this is that some of the students who just hated it at the beginning are the ones saying: 'Can I write a note about this in Knowledge Forum that we can build on?",

Reflection is further enhanced through use of formal and informal data to evaluate knowledge building processes and outcomes, including pre- and post-tests, knowledge building portfolios (van Aalst \& Chan, 2007), and careful listening to and reading of student ideas in classroom and online discourse, and feedback generated by the analytic tools. All of the teachers in this study emphasized integrating research and teaching so that reflection on and improvement of teaching is informed by learning principles and rich classroom data. These teachers, as well as 
teachers from other international sites (Lamon et al., 2005), highly value the use of the analytic tools underlying Knowledge Forum. These tools provide ongoing feedback about student participation and interaction (e.g., note contribution, writing, semantic mapping of discourse, social networks of note reading and building on) that help teachers and their students reflect on classroom processes and identify opportunities for improvement.

Continual improvement to and reflection on classroom processes help deepen and elaborate principles such as Knowledge Building discourse, so it becomes clearer what the principles mean and do not mean, what they imply for work in different contexts and styles of teaching, what can be achieved at different age levels and in different content areas, and so forth. For example, the teachers' early understanding of Knowledge Building discourse tended to focus on enabling inclusive and open conversations in which everyone expresses a theory without being judged by the teacher. This understanding was deepened by additionally recognizing the importance of examining theories in light of growing evidence to develop increasingly powerful and coherent explanations. The teachers also realized that Knowledge Building discourse could be enabled through a more or less "quiet" form of facilitation depending on the teacher's style.

Teachers' efforts to develop principle-based improvements in classroom designs grow with teacher experience, as indicated in Table 4, leading, presumably, to the improvements in student interactivity and accomplishments identified in Part 1. In other studies we also see improvements in Knowledge Building processes leading to increased collective knowledge as well as individual learning (Zhang et al., 2007; 2009; Zhang \& Sun, 2008; see also Hakkarainen, 2003). 
$\underline{\text { Knowledge Emergent through Collective Responsibility }}$

Working with a set of principles instead of pre-specified procedures, teachers perceive opportunities and demands for flexible decision-making. The process is characteristic of what Sawyer (2004) called "collaborative emergence"—or "collaborative improvisation"—in which the outcome cannot be fully predicted or specified in advance, and the process is collectively determined by all participants instead of a single, authoritative member. With the increase of collaborative emergence comes symmetry in teacher-student interactions with all contributing to the flow of conversation (Tabak \& Baumgartner, 2004), so that students can take on higher-level responsibility in deciding what and how to learn. Students contribute their diverse ideas to the community; monitor connections, gaps, conflicts, and advances; and formulate ever-deeper questions and goals. The following story from a Kindergarten classroom exemplifies the collaborative emergence of knowledge building goals and processes for deepening collective understanding.

It was the very first day of school. I thought it would be interesting to do a study of trees. ... And I tried to think where it might go... Every year in the fall, [students] bring in different colors of leaves, they look at the shapes...I think I would probably be talking about leaves and colors and maybe get to the cells... So the very first day, I started asking kids what they knew about trees. And as they told me about different parts of trees, I drew on a piece of chart paper. So someone said branches...twigs...and then a child said: "lungs." And I just stopped... It's such a clear way that puts me in an interesting position. So I said: "Where would I put the lungs?" And she said: "I don't 
know. They have to breath, don't they? They're alive." And for the next months, we looked into how trees breathe. That's how it caught children's interests in the class. ... And it was amazing to notice that you don't have to have these arbitrary barriers, that you can study so many things: do literacy and drama, deep thinking, and specific experiments... So for me it was a huge moment as a teacher to realize just how much you can blast open the possibilities of depth and time. (Interview on November 24, 2006)

Learning designs and inquiry strategies are often co-constructed with the teachers and their students collaboratively deciding on what views should be created in Knowledge Forum, how the views should be linked, and how different groups might contribute to different facets of the community enterprise. They discuss issues such as: Are we making progress in idea improvement? What are the weak areas that need more research? What experiments need to be conducted to test our theories? When do we need a KB Talk and what should it focus on? What kinds of information should be recorded in Knowledge Forum? How should individual portfolio notes that summarize knowledge advances be organized and used? What scaffolds should be created in Knowledge Forum to support inquiry? Student input often leads to development and adjustment of inquiry plans and new insights in knowledge building. As a teacher wrote in his journal: "It was a student who suggested a math question be placed in the [Knowledge Forum] database to ensure its life span. Prior to this year, I had not attempted to "do math" on [Knowledge Forum]." The collective wisdom of the community contributes to the evolution of 
the Knowledge Building designs, strategies, and processes, making Knowledge Building practice an ever-improving endeavor.

Embracing emergence and improvisation in teaching requires the teachers to re-conceptualize their role and control in classrooms. The teacher still needs to "hold the pieces together," but not control each individual, deciding who should do what, when, and through what means. When planning and facilitating knowledge building, teachers continually assess problems in a content domain, working to identify "big ideas" that span content areas, and encouraging their students to do the same. They leave the processes open and enhance the collective responsibility of the community for evolving goals and processes. The inquiry about trees - their color, composition, living, breathing--showed how a group of Senior Kindergarteners (5-year-olds) elaborated that area of inquiry. In another example, a class of fourth-graders studied optics over a four-month period. They began with revisiting their Grade 3 inquiry on how worms sense light, and progressively considered how light travels, how shadows are created, how rainbows are made, how mirrors work, how we see colors, and so forth. Views in Knowledge Forum were created and restructured in line with their inquiry goals, with progress in understanding evident both in the discussions and in individual portfolios that summarized their knowledge of light (Zhang et al., 2009; 2007). As reflected in results reported for Part 1, engagement of students in formulating goals and problems and evolving inquiry and participation procedures increases chances for them to identify, explore, and connect different issues and contribute to conceptual connectedness and depth. Thus the curriculum becomes a progressive, unfolding process driven by student thinking and conversation. 
The teachers have embraced emergence and improvisation, which makes their teaching more adventurous (Cohen, 1989). Their comfort level increases as a result of their trust in student agency and positive results of opportunistic, collective inquiry. As a Grade 5/6 teacher commented on his advances of teaching:

The other thing ... is the control. As a teacher when you're early in your career, you want...the principal to come to your room, and you're able to say: "Everybody is writing that right now." You know, that's safe. Knowledge Building is not like that. ... So I learned to really have to face what students do.... So the students thought they were reading an article about something, then new question appeared. They could actually go and do something else. So as a teacher I have to learn that it's OK to say: "I'm not sure what that group is doing." I can go and find out and ask them. I know that they were able to answer it... They are able to go deeply, because they have been given the opportunity to do that. (Interview on November 24, 2006)

\section{Variations and Challenges across Contexts Approached from a Coherent Systems Perspective}

Teachers juggle many goals and demands that require moment-to-moment decisions and trade-offs (Hammerness et al., 2005; Jackson, 1974). Knowledge Building adds innovation with classroom processes and new knowledge media to the multiple, changing demands and time commitments teachers face. In this section we elaborate some of these challenges. It is important to note, however, that despite facing substantial challenges the teachers do not convey a feeling of being overwhelmed; rather, they understand that they are working within a complex system. 
The advantage, as they see it, is that they are able to generate coherent solutions to interrelated problems and to work with autonomy and pride in facing challenges of the following sort.

In an ideal technology-facilitated classroom every child would have a computer that never crashed or lost its Internet connection, students would never forget their passwords, and there would be a committed technology coordinator to address problems that occur. But the reality at Jackman ICS, as elsewhere, is that the number of computers is limited, connections to the Internet are not as reliable as they should be, students forget their passwords, and the librarian needs to double as a technology coordinator. These problems are magnified in a Knowledge Building setting by the fact that technology is integral to day-to-day work rather than a special-purpose add-on. Teachers accordingly need to develop flexible schedules to assure all students have access to Knowledge Forum through the five or so desktop computers available in their classes. They need to develop work around strategies when there is no Internet access; for example, students are asked to make hand-written notes and later transfer their ideas to the community space. And special support for students at lower grade levels is required to help them write and save their notes. As reflected in a journal entry of a Grade 2 teacher who was in the first year of using Knowledge Building pedagogy, second-graders were not comfortable typing, so they could not enter their ideas into Knowledge Forum. After talking to her colleagues at a meeting, she decided to address this challenge using several strategies, also recorded in her journal:

"Children who want to will type their notes themselves. When children are on the database, adults [the teacher and her intern] may come and offer to take over the typing for a period of 
time or to help them to finish off their note if time is running out or if the child seems to be tiring. Children may request that an adult type the entire note for them. Children may write the note by hand and have an adult enter it into the database as the child reads it aloud." (Teacher journal, November 23, 2003)

Another practical constraint is time, as teachers engage in Knowledge Building and do so in addition to all of the typical demands on teacher time such as unexpected events, field trips, time with parents, and so forth. To accommodate these different demands teachers adopt creative and flexible scheduling procedures and focus on cross-disciplinary inquiries that integrate multiple goals (e.g. non-fiction writing and science inquiry), and work with "big ideas" that help coordinate work across domains.

Despite such challenges teachers focus on the coherence of their work, not on being overwhelmed. They see their work in keeping with the philosophy of the school which is "education for all," aiming to understand and respond to the needs of individual students and promote their development in all aspects: social, cognitive, emotional, and physical. Dealing with behavioral problems is part of the Knowledge Building challenge, as it is essential to create an accepting, caring, and responsible community to collaboratively build and share knowledge. Teachers report that their goals come together when students respect, care about, listen to each other's ideas and feelings, make reflective and fair decisions, and take responsibility for the conditions and outputs that allow every student to be an active member of the community. 
Teacher Professional Knowledge Building Communities Reflect a Commitment to Continual $\underline{\text { Improvement of Teaching Practices and Achievements }}$

Teachers participate in weekly Knowledge Building meeting to talk about their problems of understanding and knowledge advances; to share plans, actions, observations, reflections; and to discuss difficulties and technological issues. As indicated above, the Knowledge Society Network provides an international forum of Knowledge Building researchers, teachers, students, and professionals and includes virtual tours of work in Knowledge Forum (http://ikit.org/mvt/). Most teachers within the school maintain a reflection journal, called "Calendar of Inquiry (COI)," in Knowledge Forum, which is accessible to colleagues and researchers. Through these different means teachers find partners to explore possibilities of cross-disciplinary, cross-classroom connections (e.g., a grade 5/6 teacher collaborated with the physical education teacher to facilitate inquiry of human body), to experiment with new design ideas, and to address common challenges. Their sharing, conversation, and collaboration help to interweave their individual innovative efforts and increase the collective capacity of this teacher community.

“There are so many ideas, so much experience ... so much willingness and enthusiasm to follow something through. Anytime I have an idea, a question and I want to connect with another class or another teacher, you pretty much have people who are willing to go ahead and do it." (Interview with a Kindergarten teacher, November 24, 2006)

At the meetings, the teachers test limits; they are dedicated to productive disequilibrium (Wilson \& Berne, 1999) that helps them achieve new insights and improve their practice each 
year. As a Grade 3 teacher said: "Everybody here is so interested in their teaching and improving it. And people will talk about things that didn't go well. There's not a sort of pretending that everything is great." A similar point was made by a Grade 1 teacher by saying: "I often will reflect on what the stumbling blocks are, talk to colleagues, reflect on their views, work again in the classroom, and then attempt to move forward with new ideas."

The rich, open conversations and sharing in this professional community provide apprenticeship support for new teachers as they get started. They can observe practices in different grades and content areas, understand the richness and complexity of authentic classroom problems (Putnam \& Borko, 2000), access diverse design strategies and expertise of experienced teachers, and receive feedback from them. For example, a new Grade 1 teacher reflected in her journal:

Now that I have seen what happens after N's (a Grade 2 teacher) KB Talk, I feel like there is a piece that I can include to allow every child to connect with the information. The two things that she does are: Asking a child to summarize the big ideas of the talk... Even more importantly, the other thing $\mathrm{N}$ does... in asking them to go off after a talk...to draw something they learned in the talk is such a great idea! So there is a record and a way to access each child's thinking, and this will let me see what kids are coming out of the talk with, and where communication broke down, and allow me to try to create an experience in a KB Talk where as many children as possible have something to connect to. Exciting! 


\section{Leadership Reflects a Commitment to Innovation at All Levels}

Interview responses from teachers converge on the importance of the principal's leadership in sustaining knowledge building, revealing several important aspects of her leadership. These included (a) providing support for research, collaboration, and innovation across contexts; (b) communicating high expectation for teaching excellence and autonomous action; (c) encouraging exploration of new ideas and conveying trust in teachers; (c) creating social structures and opportunities for teachers to share and talk about their ideas and practices; (d) participating in teacher meetings so as to understand advances and challenges and contribute to them; (e) conducting professional and pedagogical conversations with individual teachers regarding classroom teaching, student learning, and teacher development, as opposed to "administratively" oriented talks (Chesler, Schmuch, \& Lippitt, 1963); (f) providing financial resources and release time to support teacher development (e.g., visiting other classrooms and schools, presenting at conferences); and $(\mathrm{g})$ connecting with research and professional organizations and interacting with students' families to obtain external support. These roles focus on creating a vibrant, supportive, and collaborative school environment and mobilizing collegial interactions, idea contact, and experimentation. Teachers are encouraged to expose their problems, experiment with new ideas and designs, and sustain collegial dialogue and critical reflection.

"The notion of improvable ideas [a Knowledge Building principle] fits perfectly with the sense that we are always going to be improving our practice. We encourage dialogue among the teachers about how they solve their own problems... We assume there will be problems of understanding. You are not the best teacher if you don't have a problem of 
understanding. We are inviting you to share those problems and come together to solve them.” (Interview with the principal on December 1, 2006)

Overall, analyses of teacher and principal interviews convey the interconnected and supportive nature of the work of teachers, students, and the principal, so as to create school conditions that sustain their work. For example, the teachers' ownership and agency over teaching practice is supported through a professional community that values critical dialogue, risk-taking, and experimentation and that is fostered through a principal who believes in and fosters teacher autonomy. Similarly, the teachers embrace the idea of emergence, augmented through trust in student agency, rewarded by responsible action on the part of students and help from them in evolving new strategies. A coherent system of affordances for Knowledge Building operates at the individual, community, and international level.

\section{Discussion: The Possibility and Processes of Principle-Based Innovation}

Through analysis of 39 Knowledge Building initiatives of nine teachers over eight years this study demonstrated sustained advancement of Knowledge Building as a principle-based, school-wide innovation. Natural growth—or mastering the craft of teaching — is often associated with stabilization of procedures and smoother performance (Bereiter, 2002), which is a manifestation of "bundles" of pedagogical content knowledge built through repetitive teaching (Ball \& Bass, 2000). Rather than routinization of procedures, qualitative analyses revealed that the teachers in this study actively worked to continually improve their practices and deepen their understanding of Knowledge Building principles through collaborative improvisation. They 
experimented with new ideas and designs to evolve increasingly effective practices. Their efforts were advanced through open sharing of ideas with other teachers, making use of constructive criticism, and collaborative problem finding and problem solving. They developed progressive, adaptive expertise (Crawford et al., 2005) that is needed to advance principle-based innovations and see them through to effective practice (Zhang, 2010; c.f., Randi \& Corno, 1997).

Data analyses for Part 1 of the study focused on student achievement as reflected in their discourse in Knowledge Forum. Students contributed notes interactively and provided complementary input to peers, taking up each other's questions, providing helpful resources and commentary for each other's theories, and so forth. Through analysis of contributions and social networking within the community knowledge space it was possible to determine that students were engaged in work of growing scope and depth, taking collective responsibility for knowledge advances.

Data analyses in Part 2 revealed six interconnected themes underlying Knowledge Building as a principle-based innovation. At the most basic level Knowledge Building principles become “thinking devices" (Wertsch, 1998) to help focus and inform teachers' pedagogical thinking, decision-making, experimentation, and reflection on practice. The principles serve as design ideals and challenges to set the stage for sustained improvement of practice. At this level contributing factors include teachers' trust in students' capabilities and efforts to continually turn greater agency over to them; ever-deepening understanding of Knowledge Building aided by design, reflection and research; and teacher willingness to embrace emergence and foster student collective responsibility for co-evolving classroom processes. Knowledge Forum technology 
helps to convey the principles and their operations through a socio-technological framework that gives student ideas a dynamic public life, with automated feedback to aid reflection.

At the community level, Knowledge Building innovation is supported by principle-based discourse among the teachers and students, with the Knowledge Building principles becoming conceptual objects providing a common language and shared goals-ideals to strive for as they collaboratively deepen the meaning of the principles and co-develop designs, strategies, and resources (e.g., virtual tours at http://ikit.org/mvt). The principles—-for example, epistemic agency, continual idea improvement, Knowledge Building discourse, collective responsibility for community knowledge — become part of their professional life which includes their students and the entire teacher community, and extends to systems of support and contribution to the broader international community.

At the school level, the Knowledge Building principles help to establish social and cultural norms conducive to creative knowledge work at classroom and teacher-community levels. The principal plays a critical role in evolving a school culture supportive of Knowledge Building. She supports efforts of the individual teachers within their local community and including dynamic interactions with communities beyond the school walls. The school environment supports research, innovation, and high expectations for student achievement. These expectations are reflected in student advances, as seen in research results from Part 1. Collaboration, professional discourse, creativity, autonomy, flexibility, and collective responsibility become social values and norms, as well as criteria in hiring new teachers.

The literature on effective schools and teacher learning communities characterizes the work 
in this school: shared visions and high expectation of student achievement, reflective practice and ongoing revision of it, collegial sharing and professional dialogues, dedicated leadership, and in some cases, deliberate experimentation and daring to change (e.g., Darling-Hammond \& McLaughlin, 1995; McLaughlin \& Talbert, 2001; Pressley, Gaskins, Solic, \& Collins, 2006; Wilson \& Berne, 1999). The "no child left behind" concept is realized through empowering all students to take on high-order epistemic responsibilities (Chinn, \& Malhotra, 2002). The professional Knowledge Building discourse in the teacher community also goes beyond sharing of resources and practices to incorporate classroom management and other practical considerations requiring progressive problem solving.

Two interconnected processes drive principle-based innovation. First, teachers deepen their understanding of underlying principles through inventing, elaborating, and improving classroom designs in accordance with Knowledge Building principles and reflecting on "big ideas" surrounding classroom processes ( epistemologies that guide their practice, the role of the teacher, curriculum-learning progressions, and so forth). Their beliefs and approach are treated as improvable; their expectation is that these will be advanced through research, personal reflection, experimentation, professional dialogues, and collaborative problem solving. Classroom activities and procedures are continually improved and adapted in light of feedback resulting in deepening pedagogical understanding. The teachers transcend the boundary between pedagogical principles and practice (Hong et al., 2009) and simultaneously transform cultural beliefs and practices.

Second, teachers engage in high-level collaborative improvisation with student input to the evolution of Knowledge Building goals, designs, social configurations, specific activities, and 
evaluations. Collaborative improvisation does not exclude repeated use of effective procedures. As Sawyer (2007) quoted from the jazz bassist Charles Mingus: "You can't improvise on nothing, man, you've gotta improvise on something." (p. 170) An evolving, shared repertoire of design strategies characterizes much of the work in Knowledge Building communities: face-to-face discourse (KB Talk), online discourse (Knowledge Forum), cooperative analysis of difficult texts, experimentation, and so forth. Through mindfully considering how knowledge-creating organizations operate, mining research literature on effective knowledge building practices, and reflecting on experience, teachers and their students develop expectations for how to contribute, how to work with idea diversity and authoritative sources, how to interpret evidence and inconsistent findings, and so forth. Shared, principled understanding supports mindful, adaptive, and improvable work (Kolodner \& Gray, 2002; Zhang, 2010), so that unproductive activities are quickly eliminated or improved and procedures with strong parallels to knowledge work in out-of-school contexts are developed.

Defining classroom activities and procedures to help teacher adopt and implement educational innovations represents one way to support educational innovation in schools, with strength in easing start-up. This study highlights a different approach, one that relies on teacher and student invention and ownership of new principle-based practices in support of sustained innovation. The positive results reported are based on work at a school that provides a supportive context for innovation. Instead of asking whether this approach is generalizable, we believe a more productive question is: how can we make this model work more generally. As elaborated in the introduction, finding an answer is expected to have important implications for education in a 
knowledge-based society. Clearly further research is needed at all levels. A principle-based approach to innovation would surely face greater challenges in the "supermarket" of schooling dominated by centralized bureaucratic control, traditional assessment, and fixed schedules (Cohen, 1988). Nonetheless, the work has taken hold in schools in various locations around the world, with a number of longstanding (6 to 12 years) and continuing school-university-government partnerships and professional development initiatives (Laferrière et al., in press; Chan et al., 2008). The current study suggests the forms of organizational and structural change that could enable shared authority, greater flexibility and decentralization, and bottom-up inventiveness in educational systems (Cohen, 1988; Collins \& Halverson, 2009; Darling-Hammond, 1997; Ouchi \& Segal, 2003). Chan (2008) documented similar transformative processes by a Chinese teacher to address local constraints and enact Knowledge Building principles in a didactic educational culture. Sixteen articles in a special issue of Knowledge Building, Canadian Journal of Learning and Technology (http://www.cjlt.ca/index.php/cjlt V36(1) Fall 2010, convey advances across disciplines and countries; other studies examine Knowledge Building in diverse and international contexts (e.g. Aalst \& Truong, in press) and provide elaborated accounts of knowledge productivity and new strategies to scaffold Knowledge Building (Zhang \& Messina, 2010). Long-term initiatives are important in light of the finding of greater gains for students associated with more years of teacher experience in a progressive knowledge-advancing enterprise.

\section{Acknowledgements}

This research was funded by an Initiative on the New Economy (INE) Grant from the 
Social Sciences and Humanities Research Council of Canada (512-2002-1016). We owe special thanks to the students and teachers of the Dr. Eric Jackman Institute of Child Study of the University of Toronto for the insights, accomplishments, and research opportunities enabled by their work. We also extend our thanks to Yongcheng Gan and Lynne Johns for their assistance in data collection and analysis; and to Katerine Bielaczyc, Allan Collins, the editors, and the anonymous reviewers for their comments on draft documents.

\section{References}

Amar, A.D. (2002). Managing knowledge workers: Unleashing innovation and productivity. Westport, CT: Quorum Books.

Ball, D. L., \& Bass, H. (2000). Interleaving content and pedagogy in teaching and learning to teach. In J. Boaler (Ed.), Multiple perspectives on mathematics (pp. 83-104). Norwood, NJ: Ablex Publishing.

Ballantyne, S., McLean, S.V., \& Macpherson, I. (2003). Knowledge and skills required for creating a culture of innovation: Supporting innovative teaching and learning practices. A document prepared for the Department of Education, Science, and Training, Australian Government.

Barab, S. A., \& Luehmann, A. L. (2003). Building sustainable science curriculum: Acknowledging and accommodating local adaptation. Science Education, $\underline{87(4), 454-467 .}$ Bereiter, C. (2002). Education and mind in the knowledge age. Mahwah, NJ: Erlbaum. Bereiter, C., \& Scardamalia, M. (1987). The psychology of written composition. Hillsdale, NJ: Erlbaum. 
Bereiter, C., \& Scardamalia, M. (1993). Surpassing ourselves: An inquiry into the nature and implications of expertise. La Salle, IL: Open Court.

Bielaczyc, K., \& Collins, A. (2006). Technology as a catalyst for fostering knowledge-creating communities. In A. M. O'Donnell, C. E. Hmelo-Silver, \& J. van der Linden (Eds.), Collaborative learning, reasoning, and technology. Mahwah NJ: Erlbaum.

Brown, A. L., \& Campione, J. (1996). Psychological theory and the design of innovative learning environments: On procedures, principles, and systems. In L. Schauble \& R. Glaser (Eds.), Innovations in learning: New environments for education (pp. 289-325). Mahwah, NJ: Erlbaum.

Brown, A. L., \& Campione, J. C. (1994). Guided discovery in a community of learners. In K. McGilly (Ed.), Classroom lessons: Integrating theory and practice (pp. 201-228). Cambridge: MIT Press.

Brown, M., \& Edelson, D. C. (2001, April). Teaching by design: Curriculum design as a lens on instructional practice. Paper presented at the Annual meeting of the American Educational Research Association, Seattle, WA.

Burtis, J. (2002). Analytic toolkit for Knowledge Forum. Toronto: Institute for Knowledge Innovation and Technology, the University of Toronto.

Caswell, B., \& Bielaczyc, K. (2002). Knowledge Forum: Altering the relationship between students and scientific knowledge. Education, Communication and Information, $\underline{3}$, 281-305.

Chan, C. K. K. (2008). Pedagogical transformation and knowledge-building for the Chinese learner. Evaluation and Research in Education, 21, 235-251. 
Chan, C. K. K., van Aalst, J., \& Law, N. (2008). Developing principle-based understanding for knowledge-building in a teacher community. Paper presented at the Annual Meeting of American Educational Research Association, New York.

Chesler, M., Schmuck, R., \& Lippitt, R. (1963). The principal's role in facilitating innovation. Theory into Practice, 2(5), 269-277.

Chinn, C., \& Malhotra, B. A. (2002). Epistemologically authentic inquiry in schools: A theoretical framework for evaluating inquiry tasks. Science Education, $\underline{86,175-218 .}$

Coburn, C.E. (2003). Rethinking scale: Moving beyond numbers to deep and lasting change. Educational Researcher, 32(6), 3-12.

Cohen, D. K. (1988). Educational technology and school organization. In R. S. Nickerson \& P. Zodhiates (Eds.), Technology and education: Looking toward 2020 (pp. 231-264). Mahwah, NJ: Lawrence Erlbaum Associates.

Cohen, D. K. (1989). Teaching practice: Plus que ca change.... In P. W. Jackson (Ed.), Contributing to educational change: Perspectives on research and practice (pp. 27-84). Berkeley, CA: McCutchan.

Collins, A. (1996). Design issues for learning environments. In S. Vosniadou, E. De Court, R. Glaser, \& H. Mandl (Eds.), International perspectives on the design of technology-supported learning environments (pp. 347-361). Mahwah, NY: Erlbaum.

Collins, A., \& Halverson, R. (2009). Rethinking education in the age of technology. New York: Teachers College Press.

Csikszentmihalyi, M. (1999). Implications of a systems perspective for the study of creativity. In 
R.J. Sternberg (Ed.), Handbook of creativity (pp. 313-335). Cambridge, UK: Cambridge University Press.

Crawford, V. A. (2007, May). Adaptive expertise as knowledge building in science teachers' problem solving. Paper presented at the Second European Cognitive Science Conference, Delphi, Greece.

Crawford, V. M., Schlager, M., Toyama, Y., Riel, M., \& Vahey, P. (2005, April). Characterizing adaptive expertise in science teaching: Report on a laboratory study of teacher reasoning. Paper presented at the Annual Meeting of the American Educational Research Association, Montreal, Canada.

Creswell, J. W. (2008). Educational research: Planning, conducting, and evaluating quantitative and qualitative research ( $3^{\text {rd }}$ edition). Upper Saddle River, NJ: Pearson.

Darling-Hammond, L. (1997). The right to learn: A blueprint for creating schools that work. San Francisco: Jossey-Bass.

Darling-Hammond, L., \& Bransford, J. (2005) (Eds.). Preparing teachers for a changing world: What teachers should learn and be able to do. San Francisco, CA: Jossey-Bass.

Darling-Hammond, L., \& McLaughlin, M.W. (1995). Policies that support professional development in an era of reform. Phi Delta Kappan, 76 (8), 597-604.

Dede, C. (2006). Scaling up: Evolving innovations beyond ideal settings to challenging contexts of practice. In R. K. Sawyer (Ed.), Cambridge handbook of the learning sciences (pp. 551-566). Cambridge: Cambridge University Press.

Dillenbourg, P. (2002). Over-scripting CSCL: The risks of blending collaborative learning with 
instructional design. In P. A. Kirschner (Ed.), Three worlds of CSCL. Can we support CSCL (pp. 61-91). Heerlen, Netherlands: Open Universiteit Nederland.

Dunbar, K. (1997). How scientists think: Online creativity and conceptual change in science. In T. B. Ward, S. M. Smith \& S. Vaid (Eds.), Conceptual structures and processes: Emergence, discovery and change (pp. 461-493). Washington, DC: APA Press.

Engeström, Y. (2008). From teams to knots. Cambridge, UK: Cambridge University Press.

Engle, R. A., \& Conant, F. R. (2002). Guiding principles for fostering productive disciplinary engagement: Explaining an emergent argument in a community of learners classroom. Cognition and Instruction, 20(4), 399-483.

Feiman-Nemser, S. (2001). From preparation to practice: Designing a continuum to strengthen and sustain teaching. Teachers College Record, 103, 1013-1055.

Fishman, B.J., \& Davis, E.A. (2006). Teacher learning research and the learning sciences. In R. K. Sawyer (Ed.), Cambridge Handbook of the Learning Sciences (pp.535-550)._New York: Cambridge University Press.

Florida, R. (2002). The rise of the creative class. New York: Basic Books.

Fogleman, J., Fishman, B., \& Krajcik, J. (2006). Sustaining innovations through lead teacher learning: A learning sciences perspective on supporting professional development. Teaching Education, 17(2), 181-194.

Gloor, P. A. (2006). Swarm creativity: Competitive advantage through collaborative innovation networks. Oxford, UK: Oxford University Press.

Goldman-Segall, R. (1998). Points of viewing children's thinking. Mahwah, NJ: Erlbaum. 
Hakkarainen, K. (2003). Progressive inquiry in a computer-supported biology class. Journal of Research in Science Teaching, 40(10), 1072-1088.

Hammerness, K., Darling-Hammond, L., \& Bransford, J. (with Berliner, D., Cochran-Smith, M., McDonald, M., \& Zeichner, K.). (2005). How teachers learn and develop. In L. Darling-Hammond \& J. Bransford (Eds.), Preparing teachers for a changing world: What teachers should learn and be able to do (pp. 358-389). San Francisco, CA: Jossey-Bass.

Hargreaves, D. H. (1999). The knowledge-creating school. British Journal of Educational Studies,

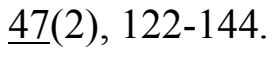

Hatano, G., \& Inagaki, K. (1986). Two courses of expertise. In H. Stevenson, H. Azuma, \& K. Hakuta (Eds.), Child development and education in Japan (pp. 262-272). New York: W. H. Freeman and Company.

Hatch, J.A. (2002). Doing qualitative research in education settings. Albany, NY: State University of New York Press.

Hitysse, G. J., \& Kennedy, S. (1999). High performing organizations. In M. J. Stahl (Ed.), Perspectives in total quality (pp. 105-133). Malden, MA: Blackwell.

Hong, H.-Y., Scardamalia, M., \& Zhang, J. (2010). Knowledge Society Network (KSN): Toward a dynamic, sustained network for building knowledge. Canadian Journal of Learning and

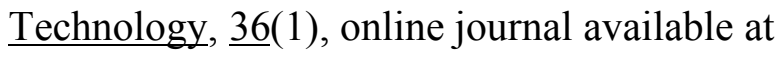
http://www.cjlt.ca/index.php/cjlt/article/view/579.

Hong, H.-Y., \& Sullivan, F. R. (2009). Towards an idea-centered, principle-based design approach to support learning as knowledge creation. Educational Technology Research and 


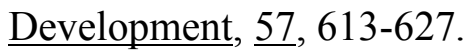

Hong, H.-Y., Zhang., J., Teo, C., \& Scardamalia, M. (2009). Towards design-based knowledge-building practices in teaching. Paper presented at the International Conference on Computer Supported Collaborative Learning (CSCL 2009). Rhodes, Greece.

Jackson, P. W. (1974). Life in classrooms. New York: Holt, Rinehart \& Winston.

Kali, Y., (2006). Collaborative knowledge-building using the Design Principles Database. International Journal of Computer Support for Collaborative Learning, 1, 187-201.

Kolodner, J. L. (2006). Case-based reasoning. In R. K. Sawyer (Ed.), Cambridge handbook of the learning sciences (pp.225-242). Cambridge, UK: Cambridge University Press.

Kolodner, J.L., Camp, P.J., Crismond D., Fasse, B., Gray, J., Holbrook, J., Puntembakar, S., Ryan, M. (2003). Problem-based learning meets case-based reasoning in the middle-school science classroom: Putting Learning by Design ${ }^{\mathrm{TM}}$ into practice. Journal of the Learning $\underline{\text { Sciences, }} \underline{\text { 12(4), }} 495$ - 548.

Kolodner, J. L., \& Gray, J. T. (2002). Understanding the affordances of ritualized activity structures for project-based classrooms. In P. Bell, R. Stevens \& T. Satwicz (Eds.), Keeping Learning Complex: International Conference of the Learning Sciences (ICLS) (pp. 221-228). Mahwah, NJ: Lawrence Erlbaum Associates.

Krajcik, J. S., Blumenfeld, P. C., Marx, R. W., \& Soloway, E. (1994). A collaborative model for helping middle grade science teachers learn project-based instruction. The Elementary School Journal, 94, 483-497.

Laferriere, T., Breuleux, A. \& Allaire, S. (2007). Teaching as a visible activity in remote 
networked schools: A socio-cultural perspective. In G. Richards (Ed.), Proceedings of World Conference on E-Learning in Corporate, Government, Healthcare, and Higher Education 2007 (pp. 6846-6852). Chesapeake, VA: AACE.

Laferrière, T., Montané, M., Gros, B., Alvarez, I., Bernaus, M., Breuleux, A., Allaire, S., Hamel, C., \& Lamon, M. (2010). Partnership for knowledge building: An emerging model. Canadian

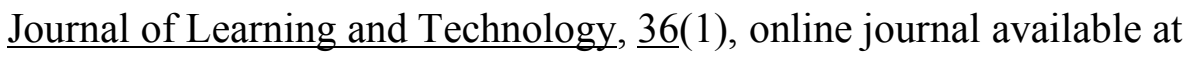
http://www.cjlt.ca/index.php/cjlt/article/view/578 .

Lamon, M., Laferriere, T., \& Scardamalia, M. (1995). Teacher expertise as progressive problem solving. Paper presented at the Annual Meeting of the American Educational Research Association, Montreal, Canada.

Lampert, M. (1999). Knowing teaching from the inside out: Implications of inquiry in practice for teacher education. In G. Griffen (Ed.), The education of teachers: 98th Yearbook of the National Society for the Study of Education, Part 1 (pp. 167-184). Chicago, IL: University of Chicago Press.

Linn, M. C. (2006). The knowledge integration perspective on learning and instruction. In R. K. Sawyer (Ed.), Cambridge handbook of the learning sciences (pp.243-264). Cambridge: Cambridge University Press.

Little, J.W. (2002). Locating learning in teachers' communities of practice: opening up problems of analysis in records of everyday work. Teaching and Teacher Education, 18(8), 917-946. McLaughlin, M.W., \& Talbert J.E. (2001). Professional communities and the work of high school teaching. Chicago, IL: The University of Chicago Press. 
Ouchi, W., \& Segal, L. (2003). Making schools work: A revolutionary plan to get your children the education they need. New York: Simon and Schuster.

Palincsar, A.S., Anderson, C.W., \& David, Y. (1993). Pursuing scientific literacy in the middle grades through collaborative problem solving. Elementary School Journal, $\underline{5}, 643-658$.

Pelletier, J., \& Reeve, R., \& Halewood, C. (2006). Young children's knowledge building and literacy development through Knowledge Forum. Early Education and Development, 17, 323-346.

Penuel, W. R., \& Gallagher, L. P. (2009). Preparing teachers to design instruction for deep understanding in middle school earth science. Journal of the Learning Sciences, $\underline{18}$, 461-508.

Pressley, M., Gaskins, I. W., Solic, K., \& Collins, S. (2006). A portrait of Benchmark School: How a school produces high achievement in students who previously failed. Journal of Educational Psychology, 98, 282-306.

Putnam, R. T., \& Borko, H. (2000). What do new views of knowledge and thinking have to say about research on teacher learning? Educational Researcher, 29(1), 4-15.

Randi, J., \& Corno, L. (1997). Teachers as innovators. In B. J. Biddle, T. L. Good, \& I. F. Goodson (Eds.), The international handbook of teachers and teaching (Vol. II, pp. 1163-1221). Dordrecht, The Netherlands: Kluwer.

Reeve, R. (2001). The knowledge building lab school: Principles in practice. In New Directions in Knowledge Building, a symposium at the annual meeting of the American Educational Research Association, Seattle, WA. 
Rodgers, C. (2002). Seeing student learning: Teacher change and the role of reflection. Harvard Educational Review, 72, 230-253.

Russell, S. J. (1998). Mathematics curriculum implementation: Not a beginning, not an end. Hands On!, 21(1), 6-9.

Sawyer, R.K. (2004). Creative teaching: Collaborative discussion as disciplined improvisation. Educational Researcher, 33(2), 12-20.

Sawyer, R.K. (2007). Group genius: The creative power of collaboration. New York: Basic Books.

Scardamalia, M. (2002). Collective cognitive responsibility for the advancement of knowledge. In B. Smith (Ed.), Liberal education in a knowledge society(pp.67-98). Chicago, IL: Open Court

Scardamalia, M. (2003). Going beyond best practice: Knowledge building principles and indicators. Paper presented at the Knowledge Building /Knowledge Forum Summer Institute. Toronto. Online available at: http://ikit.org/SummerInstitute2003/posters/kbindicators.html. Scardamalia, M. (2004). CSILE/Knowledge Forum ${ }^{\circledR}$. In A. Kovalchick, \& K. Dawson (Eds.), Education and technology: An encyclopedia (pp. 183-192). Santa Barbara, CA: ABC-CLIO, Inc.

Scardamalia, M., \& Bereiter, C. (1991). Higher levels of agency for children in knowledge building: A challenge for the design of new knowledge media. Journal of the Learning Sciences, $\underline{1,37-68 .}$

Scardamalia, M., \& Bereiter, C. (1996). Engaging students in a knowledge society. Educational 
Leadership, $\underline{54}$ (3), 6-10.

Scardamalia, M., \& Bereiter, C. (2003). Knowledge building. In J. W. Guthrie (Ed.),

Encyclopedia of Education ( $2^{\text {nd }}$ ed) (pp. 1370-1373). New York: Macmillan Reference.

Scardamalia, M., \& Bereiter, C. (2006). Knowledge building: Theory, pedagogy, and technology.

In R. K. Sawyer (Ed.), Cambridge Handbook of the Learning Sciences (pp. 97-115). New

York: Cambridge University Press.

Scardamalia, M., \& Bereiter, C. (2007). "Fostering communities of learners" and "knowledge

building": An interrupted dialogue. In J. C. Campione, K. E. Metz, \& A. S. Palincsar (Eds.),

Children's learning in the laboratory and in the classroom: Essays in honor of Ann Brown

(pp. 197-212). Mahwah, NJ: Erlbaum.

Scardamalia, M., Bransford, J., Kozma, R., \& Quellmalz, E. (2010). New assessments and environments for knowledge building. Assessment and Learning of 21 st Century Skills. Paper posted to http://www.atc21s.org/home/

Schwartz, D., Lin, X., Brophy, S., \& Bransford, J. (1999). Torward the development of flexibly adaptive instructional designs. In C. Reigeluth (Ed.), Instructional design theories and models Vol. II (pp. 183-213). Mahwah, NJ: Lawrence Erlbaum Associates

Scott, J. (1991). Social network analysis: A handbook. London, England: Sage.

Sternberg, R. J. (2003). The development of creativity as a decision-making process. In R. K. Sawyer et al. (Eds.), Creativity and development (pp.91-138). New York: Oxford University Press.

Strauss, A., \& Corbin, J. (1998). Basics of qualitative research: Techniques and procedures for 
developing grounded theory (2nd edition). Newbury Park, CA: Sage.

Sun, Y., Zhang, J., \& Scardamalia, M. (2010). Knowledge building and vocabulary growth over two years, Grades 3 and 4. Instructional Science, $\underline{38}$ (2), 247-271.

Tabak, I., \& Baumgartner, E. (2004). The teacher as partner: Exploring participant structures, symmetry, and identity work in scaffolding. Cognition and Instruction, 22(4), 393-429. Taylor, F. (1919). Principles of scientific management. New York: Harper and Brothers. Tyack, D., \& Cuban, L. (1995). Tinkering toward utopia. Cambridge, MA: Harvard University Press.

van Aalst, J., \& Chan, C.K..K. (2007). Student-directed assessment of knowledge building using electronic portfolios in Knowledge Forum. Journal of the Learning Sciences, 16, 175-220. van Aalst, J., \& Truong, M. S. (in press). Promoting knowledge creation discourse in an Asian Primary Five classroom: Results from an inquiry into life cycles. International Journal of Science Education.

Vescio, V., Rossa, D., \& Adamsa, A. (2008). A review of research on the impact of professional learning communities on teaching practice and student learning. Teaching and Teacher Education, 24(1), 80-91.

Wertsch, J.V. (1998). Mind as action. New York: Oxford University Press.

Williams, W. M., \& Yang, L. T. (1999). Organizational creativity. In R.J. Sternberg (Ed.), Handbook of Creativity (pp. 373-391). Cambridge, UK: Cambridge University Press.

Wilson, S. M., \& Berne, J. (1999). Teacher learning and the acquisition of professional knowledge: An examination of research on contemporary professional development. Review 
of Research in Education, 24, 173-209.

Zhang, J. (2009). Towards a creative social Web for learners and teachers. Educational $\underline{\text { Researcher, }} \underline{38}, 274-279$.

Zhang, J. (2010). Technology supported learning innovation in cultural contexts. Educational Technology Research and Development, 58, 229-243.

Zhang, J. \& Messina, R. (2010). Collaborative productivity as self-sustaining processes in a Grade 4 knowledge building community. In K. Gomez, J. Radinsky, \& L. Lyons (Eds.), Proceedings of the 9th International Conference of the Learning Sciences (pp. 49-56). Chicago, IL: International Society of the Learning Sciences.

Zhang, J., Scardamalia, M., Lamon, M., Messina, R., \& Reeve, R. (2007). Socio-cognitive dynamics of knowledge building in 9- and 10-year-olds. Educational Technology Research and Development, $\underline{55}, 117-145$.

Zhang, J., Scardamalia, M., Reeve, R., \& Messina, R. (2009). Designs for collective cognitive responsibility in knowledge building communities. Journal of the Learning Sciences, 18 , $7-44$.

Zhang, J., \& Sun, Y. (2008). Knowledge building measures that matter. Paper presented at the Knowledge Building /Knowledge Forum Summer Institute, the University of Toronto. 
Appendix 1. Examples of the teacher interview questions.

What are the three most important qualities you would like to develop in your students? What are the major things you do to develop these qualities?

What have been your three most important improvements in your teaching in the past years?

Please elaborate when and how these improvements happened.

From what sources did you first learn about the approach of Knowledge Building Talk (KB

Talk)? In what ways have you improved KB Talks in your classroom?

In what way do you see your colleagues as supportive of your efforts for seeking innovation in teaching? Please name at least three major aspects.

In what way do you see your principal as supportive of your efforts for innovation in teaching?

What further support from your school would you need? 

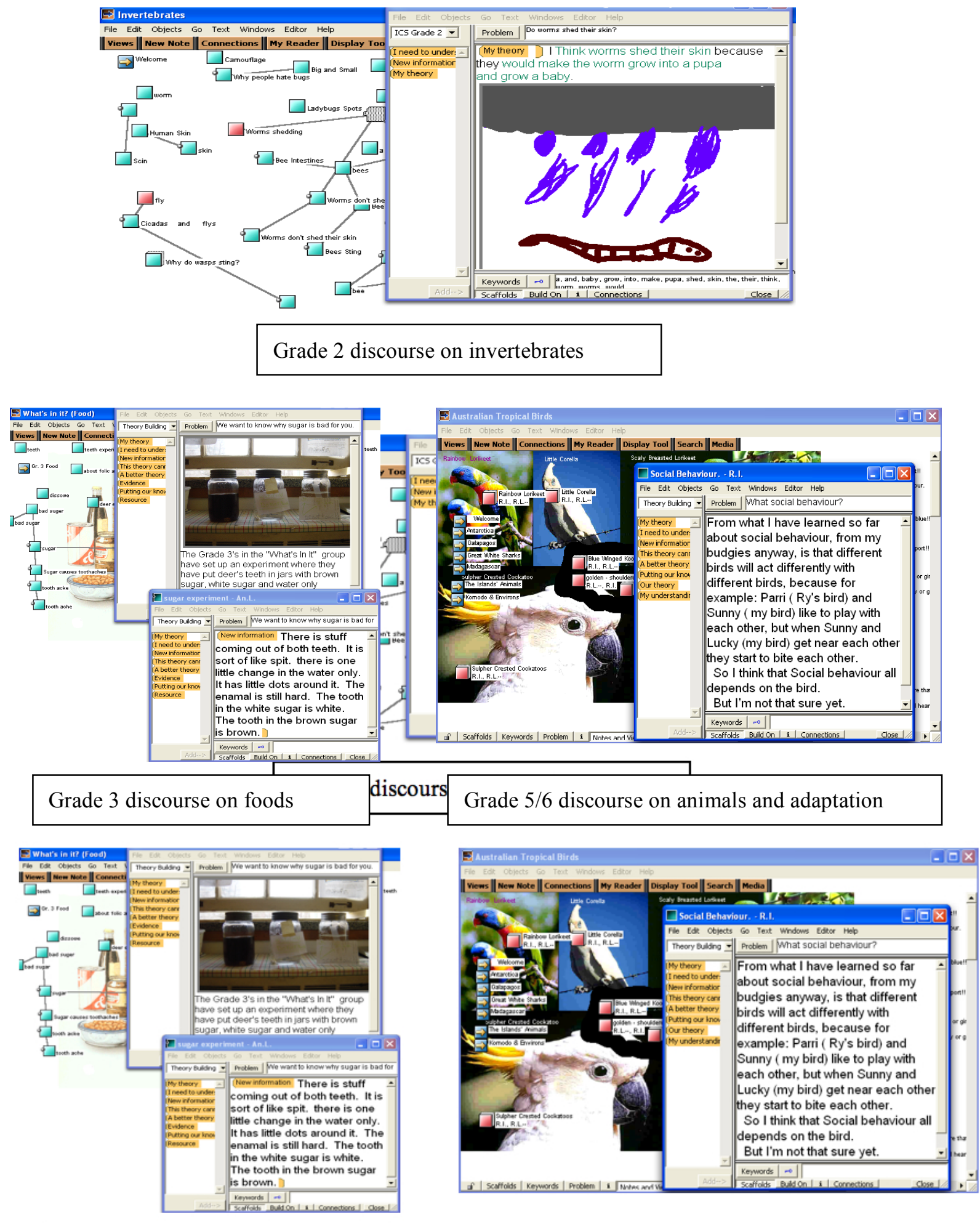

Grade 3 discourse on foods

Grade 5/6 discourse on animals and adaptation

Figure 1. Screenshots of student discourse in Knowledge Forum views (work spaces). The small

square icon in a view represents a note. A line between two notes indicates a build-on. The 
opened notes provide examples of student contributions to the Knowledge Building discourse: identifying problems; generating theories, hypotheses, and experimental evidence; reflecting on idea development, which is often enhanced through reading authoritative source material. Each Knowledge Building initiative usually involves work in multiple views that are hyperlinked. For example, the Grade 5/6 inquiry on animals and adaptation included seven hyperlinked views, including "Australian Tropical Birds" shown above, which were linked to other views: Antarctica, Galapagos, Great White Sharks, etc. 


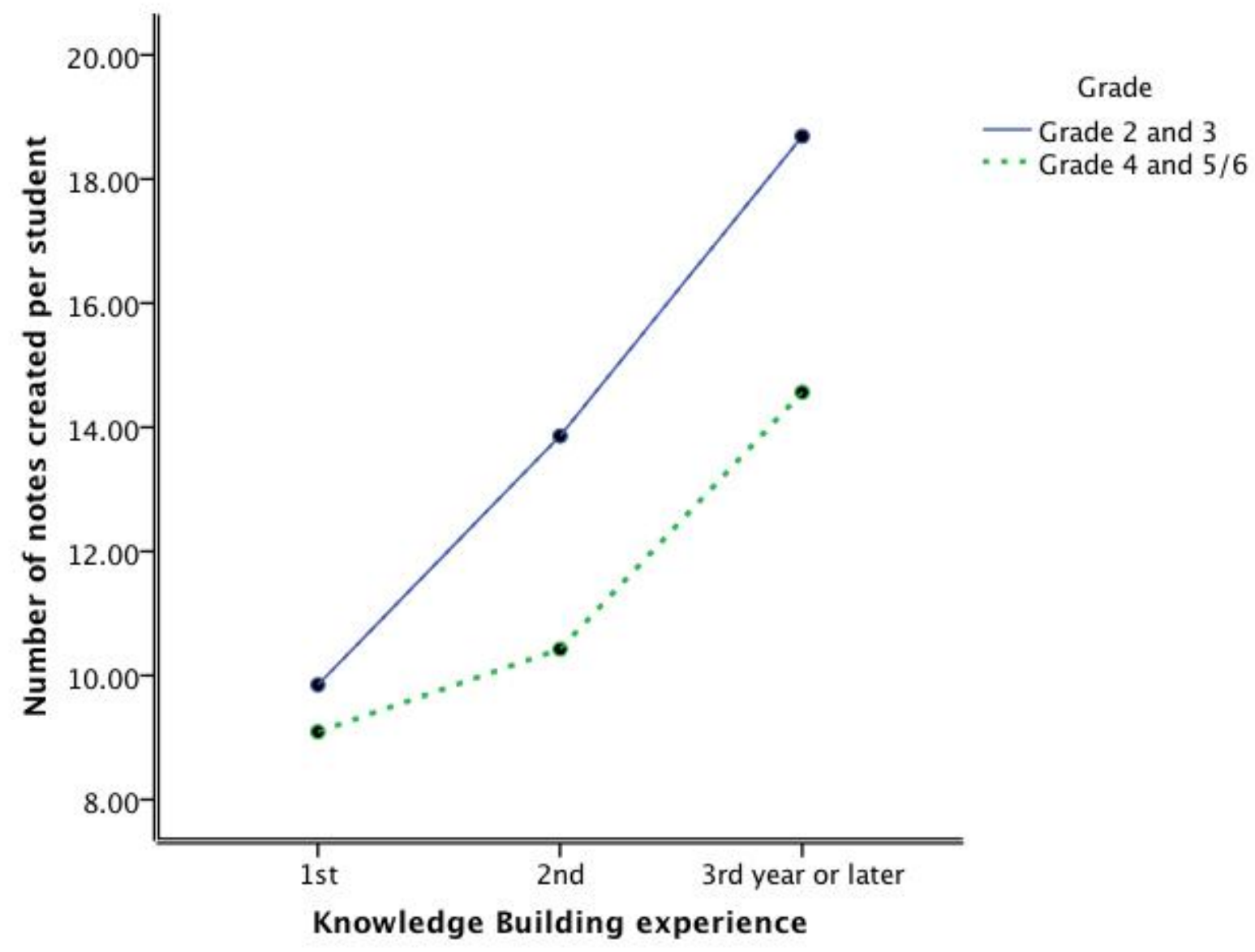

Figure 2. The average number of notes created by each student across 39 Knowledge Building initiatives facilitated by nine different teachers in their first, second, or third year (or later) of work with Knowledge Building . 


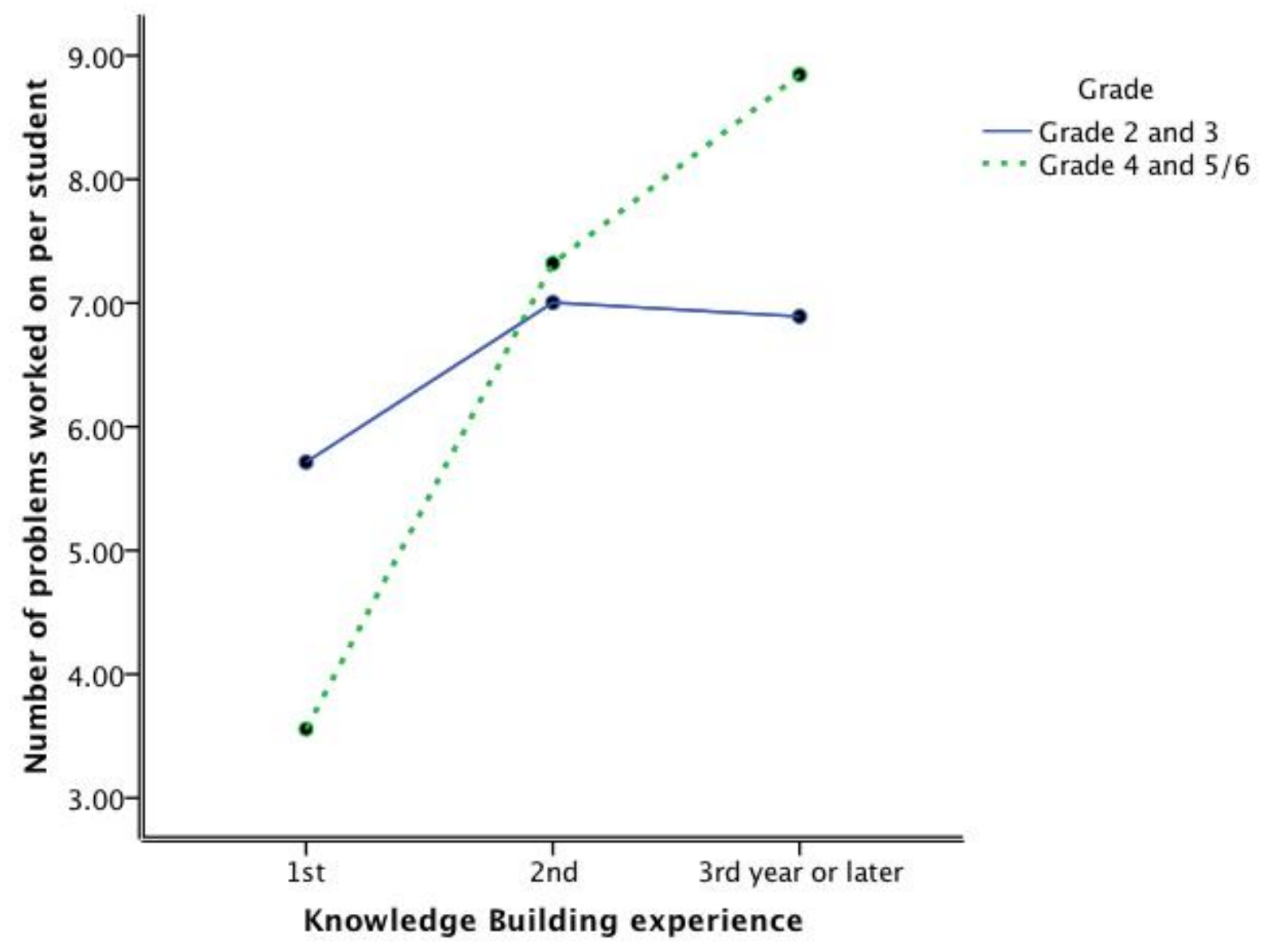

Figure 3. The number of problems worked on by each student in Knowledge Forum across 39 Knowledge Building initiatives facilitated by nine different teachers in their first, second, or third year (or later) of work with Knowledge Building . 


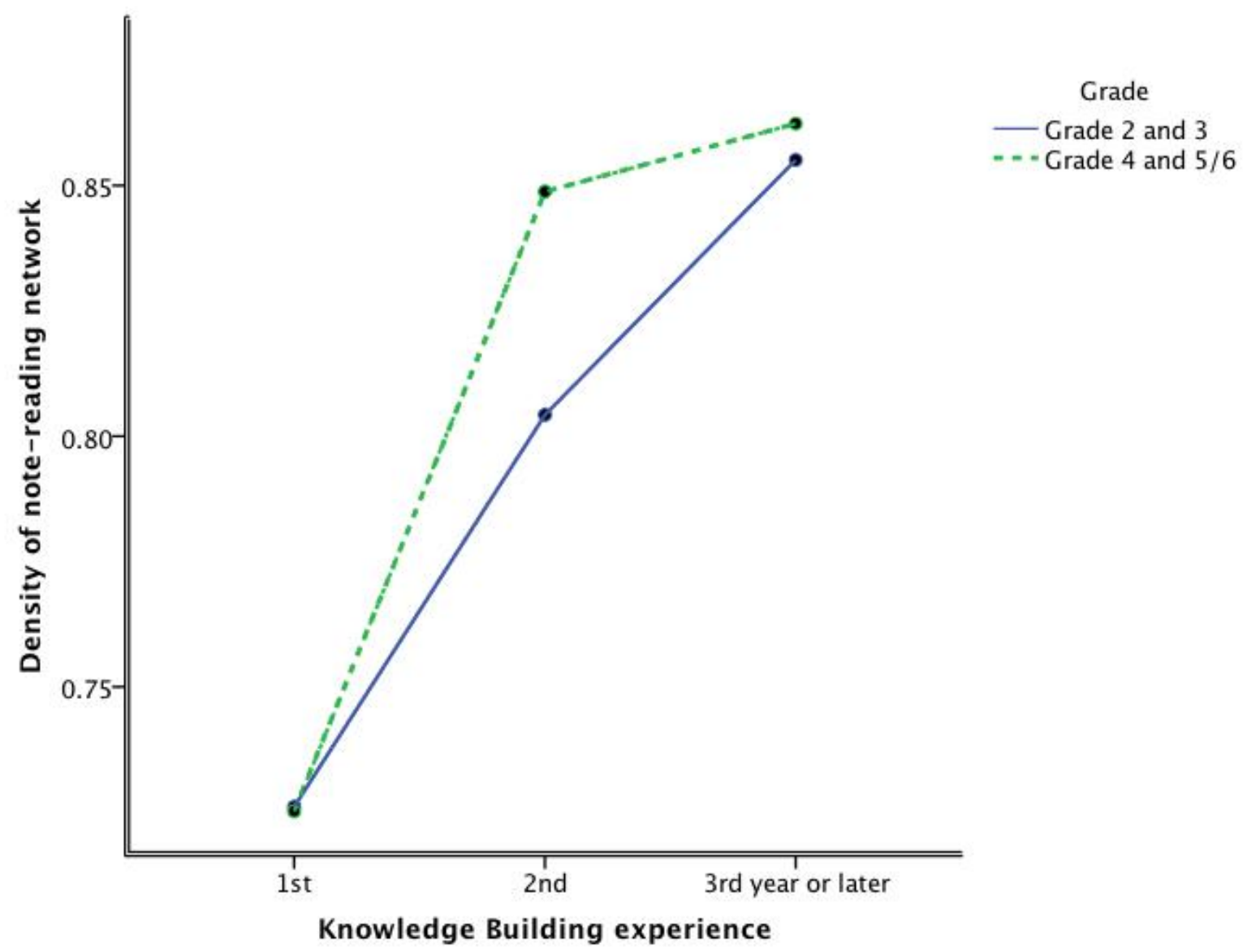

Figure 4. Densities of note reading contacts across 39 Knowledge Building initiatives facilitated by nine teachers in their first, second, or third year (or later) of work with Knowledge Building. Density of a social network is gauged by the number of node-to-node connections present divided by the maximum number of all possible connections, with a value varying between 0 and 1. 


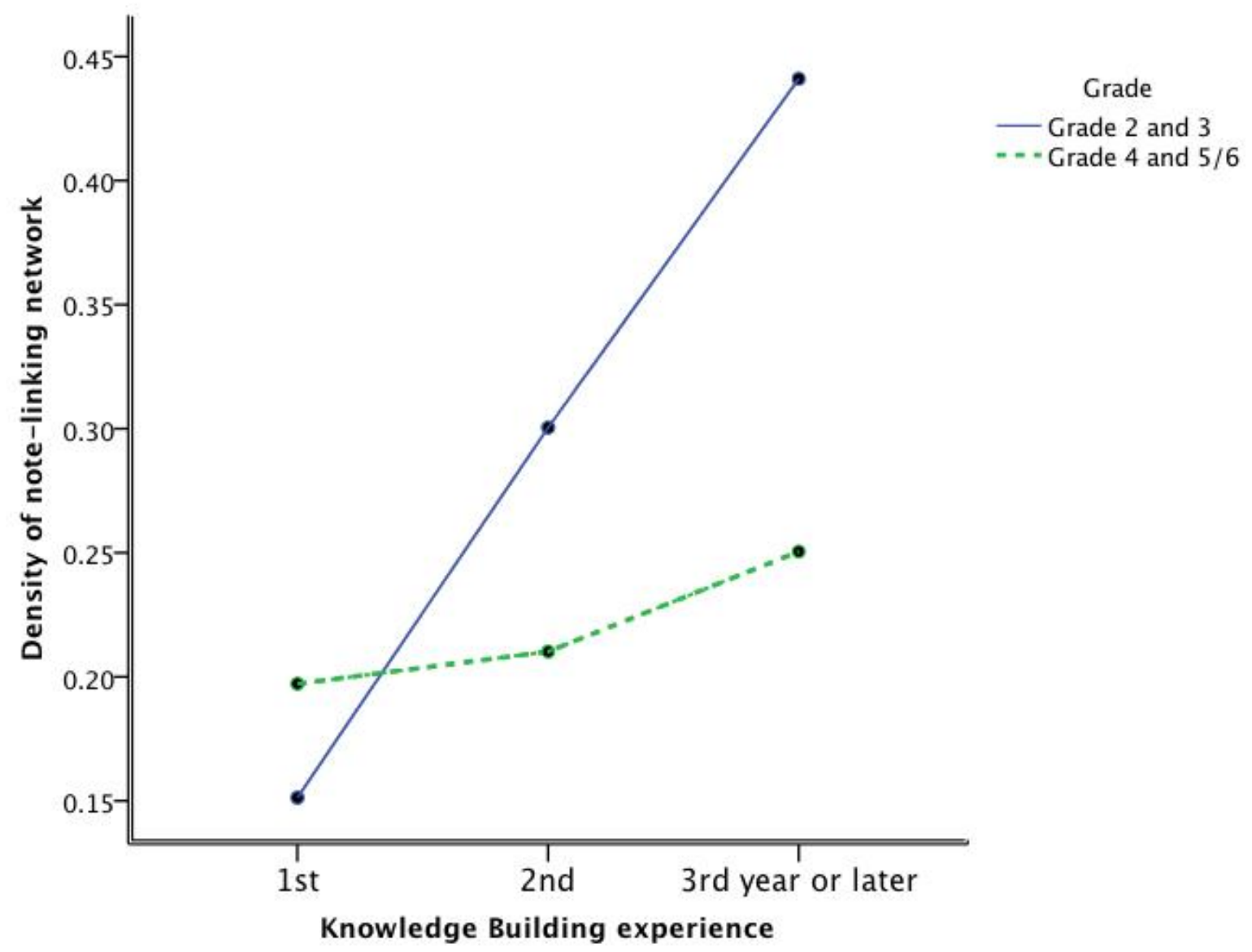

Figure 5. Density of note linking contacts across 39 Knowledge Building initiatives facilitated by nine teachers in their first, second, or third year (or later) of work with Knowledge Building. Density of a social network is gauged by the number of node-to-node connections present divided by the maximum number of all possible connections, with a value varying between 0 and 1. 
Table 1

Knowledge Building Principles and Knowledge Forum Supports: Making Principles Transparent to Teachers and Students.

Knowledge Building Principles

Knowledge Forum Supports

Real Ideas and Authentic Problems. Notes and views serve as direct reflections of the

Students identify problems that arise from core ideas and work of the community; problem their efforts to understand the world and statements and scaffolds highlight unsolved pursue sustained creative work surrounding problems, promising ideas, and other high-level them. knowledge objects.

Improvable Ideas. Ideas are treated as Note revision and scaffold enhance theory improvable rather than simply accepted or development and discourse for idea improvement; rejected; students work continuously to background analytic tools and feedback support improve the explanatory power, coherence, idea revision and monitoring of coherence among and utility of ideas. ideas.

Epistemic Agency. Students set goals, assess Analytic tools support reflection on individual their work, engage in long-range planning, and group progress; co-construction and monitor idea coherence, use contrasting refinement of theories is supported by view ideas ideas to spark and sustain knowledge in multiple contexts; scaffolds encourage use of advancement, and engage in high-level epistemological terms (e.g., conjecture, wonder, knowledge work normally left to the hypothesize) and growth in conceptual content. teacher. 
Collective Responsibility for Community Open, collaborative workspaces encourage Knowledge. All participants are legitimate production and refinement of conceptual artifacts; contributors to community goals and take reading, building on, and linking notes and views high-level responsibility for advancing the help ensure these artifacts are informative and community's knowledge, not only for their helpful for the community; social and semantic individual learning. networks and other visualizations support reflection.

Democratizing Knowledge. All participants Multimedia facilities provide a way into shared are empowered as legitimate contributors to problem spaces for all participants; analytic tools the shared goals; all take pride in knowledge provide feedback to allow participants to achieve advances of the community. Diversity and greater evenness of contributions and distributed, divisional differences are viewed as collective engagement.

strengths rather than leading to separation along knowledge have/have-not lines.

Idea Diversity. Knowledge advancement Linking and rise-above facilities bring different depends on diversity of ideas, just as the combinations of ideas together in different notes success of an ecosystem depends on and views; semantic analysis and visualizations biodiversity. To understand an idea is to convey diversity and connectedness of ideas. understand the ideas that surround it, including those that stand in contrast to it. Knowledge Building Discourse. Students Rich intertextual and inter-team notes and views engage in discursive practices that not only support emergent goals and workspaces; revision, 
share but transform and advance knowledge, build-on, reference, and annotation further with problems progressively identified and encourage participants to identify shared addressed and new conceptualizations built. problems and gaps, interweave peer input, and advance understanding beyond the level of the most knowledgeable individual.

Rise Above. Students work with diverse Higher-order overviews are facilitated through ideas in complex problem spaces; they rise-above notes and views; there is unlimited transcend trivialities and oversimplifications embedding of notes and views; flexible view and work toward more inclusive principles structures support emergent rather than fixed and higher-level formulations of problems. goals.

Constructive Use of Authoritative Sources. Reference and build-on to authoritative sources is Participants access and critically evaluate supported, with bibliographies generated authoritative sources and other information. automatically from referenced sources, to support They use these sources to support and refine contributions to community resources; their ideas, not just to find "the answer." $\quad$ identification of key terms and semantic analysis tools support reflective use of new information in discourse.

Pervasive Knowledge Building. Knowledge A communal database provides a coordinating Building is not confined to particular framework for the community's work, so occasions or subjects but pervades mental Knowledge Building is central to the enterprise life - in and out of school and across rather than an add-on; contributions to collective 
contexts.

resources reflect all aspects of knowledge work and can incorporate various forms of media objects.

Symmetric Knowledge Advance. Expertise Virtual visits and co-construction of knowledge is distributed within and between spaces support interactivity and complementary communities and team members, with work across teams, both within and between knowledge exchange and co-construction communities; symmetry in knowledge work is reflecting the understanding that "to give directly reflected in the flow and reworking of knowledge is to get knowledge." information across views and databases of different teams and communities; analytic tools provide feedback on cross-team and cross-theme interactions.

Embedded and Transformative Assessment. Standards and benchmarks are objects of Assessment is integral to Knowledge discourse, to be annotated, built on, and reflected Building and helps to advance knowledge upon; automated on-demand feedback aids through identifying advances, problems, and reflective monitoring and improvement of gaps as work proceeds. disciplinary understanding, literacy, and 21 st century skills.

Note. Adapted from Scardamalia (2002). 
Table 2

Thirty-Nine Knowledge Building Initiatives with Students Grades 2-6 Facilitated by Teachers in

Their First, Second, or Third Year (or Later) of Implementing Knowledge Building in their Classroom

Teachers' experience with Knowledge Building pedagogy

\begin{tabular}{llll}
\hline & $1^{\text {st }}$ year & $2^{\text {nd }}$ year & $3^{\text {rd }}$ year or later \\
Lower grades & 8 & 9 & 6 \\
$($ Grade 2-3) & 5 & 3 & 8 \\
Upper grades & 5 & & \\
$($ Grade 4-5/6) & & & \\
\hline
\end{tabular}


Table 3

Six Themes Underlying Knowledge Building as a Principle-Based Innovation.

\begin{tabular}{|c|c|}
\hline Themes & Sub-themes \\
\hline Shared visions, high & Shared visions of learning, teaching, and innovation; \\
\hline expectations, and agency & high expectation and trust in student agency and potential; \\
\hline \multirow[t]{4}{*}{ in knowledge work } & teacher's role viewed as releasing agency to students for high-level \\
\hline & knowledge work; \\
\hline & ownership and agency over teaching practices, seeking continual \\
\hline & improvement. \\
\hline Ever-deepening & Understanding of Knowledge Building principles as an ongoing \\
\hline understanding aided by & challenge, with the principles themselves viewed as improvable; \\
\hline design, reflection & creation and improvement of classroom designs in light of \\
\hline \multirow[t]{4}{*}{ and research } & principles, with problems viewed positively, as clues for improving \\
\hline & designs; \\
\hline & principle-based reflection on classroom processes; \\
\hline & evaluation and research integrated into classroom processes. \\
\hline Knowledge emergent & Open-ended, emergent inquiry processes, progressive curriculum; \\
\hline through collective & students help co-construct Knowledge Building goals, processes, \\
\hline responsibility & and evaluations; \\
\hline & idea diversity drives Knowledge Building; \\
\hline
\end{tabular}


teacher's role adjusted in light of Knowledge Building principles, embracing open and opportunistic planning.

Variations and challenges Multiple, changing demands in school drive innovation rather than across contexts being a barrier to it;

approached from a behavioral problems addressed through community building; coherent systems technological problems addressed through innovative designs; perspective constraint of time addressed through flexible scheduling. Teacher professional Weekly Knowledge Building meetings provide time to talk about Knowledge Building advances and challenges and to develop increasingly deep communities reflect a understanding of principles; commitment to continual collaborative planning, sharing, and review of Knowledge Building improvement of practice through online reflection journals; teaching practices and peer observation of classroom practices and collaborative achievements experimentation; critical reflection and dialogues, productive disequilibrium, risk-taking; apprenticeships for new teachers.

Leadership reflects a $\quad$ Research, collaboration, and innovation valued by the principal and commitment to teachers; innovation at all levels high expectations of teaching excellence, trust in teachers, and encouragement of risk-taking; 
principal participation in regular Knowledge Building meetings, encouraging dialogues, sharing, and collaboration; "professionally" oriented conversations with individual teachers; financial support and release time for teacher professional development; partnerships with research and professional organizations and involvement of parent communities. 
Table 4

Designs and Strategies to Support Three Knowledge Building Principles.

Principles Supportive designs and strategies

Real ideas, Contributing theories, problems of understanding, and other forms of authentic problems epistemic artifacts;

identifying "big ideas" in the curriculum and in their own contributions;

evolving inquiries by revisiting previous work or discussing current events

related to student interests (e.g., hurricane);

generating questions, formulating thematic goals, sharing initial ideas

through whole-class discussions, and working collaboratively to improve

ideas;

monitoring self and group progress of understanding and identifying deeper questions and challenges.

Collective Creating a safe and supportive community that encourages and works with

responsibility for idea diversity;

community discussing and highlighting social norms that support Knowledge Building

knowledge (e.g., respect, careful listening, detailed accounts, building on rather than

repeating what others have said);

co-creating mission statements and goals;

linking views (workspaces) in Knowledge Forum to convey interrelated knowledge goals and using background pictures to highlight themes and 
advances;

cross-referencing ideas, incremental building on, connecting current work with ideas and information in the community space (e.g., discussion notes, experimental findings, insights from readings);

using dynamic social structures that integrate whole-class discussions, small-group reading and experiments, and individual work, encouraging students to group and re-group based on evolving needs; reviewing progress as a community, sharing insights, generating excitement, and identifying new problems of understanding.

Constructive use of Highlighting questions and discussing initial ideas before students read authoritative material;

sources small-group cooperative reading of difficult texts; coaching and using strategies of deep reading (e.g., questioning, reviewing, summarizing); sharing important information from readings in Knowledge Forum and going beyond given information; collectively developing an online glossary to help community members understand the related key concepts that are used in the discourse. 